\title{
(1)
}

UNIVERSIDAD PERUANA DE CIENCAS APLICADAS

\author{
Facultad de negocios
}

Carrera de Administración y Recursos Humanos

\section{LA COMUNICACIÓN ORGANIZACIONAL Y SU INFLUENCIA EN EL CLIMA ORGANIZACIONAL DE LOS OPERARIOS DE INDUSTRIAS SAN MIGUEL EN EL 2017}

TESIS PARA OPTAR EL TÍTULO PROFESIONAL DE: LICENCIADO EN RECURSOS HUMANOS

AUTORES:

Reyes Escalante, Carol Beatriz (0000-0002-6802-0644)

Ayarza Rojas, Augusto Junior (0000-0002-3859-0654)

ASESOR DE TESIS:

Bartra Rivero, Karina Raquel (0000-0001-9879-3237)

Lima, 03 de Setiembre de 2018 
A nuestros padres y familiares

Agradecimientos

El presente trabajo de investigación está dedicado a nuestros padres, quienes nos apoyan en todo momento con los desafíos y retos que emprendemos día a día. 


\section{Resumen Ejecutivo}

En la presente investigación se determinó, mediante un alcance explicativo, con un diseño no experimental y de corte transversal, la relación causal existente entre la comunicación organizacional y el clima organizacional de los operarios de Industrias San Miguel en el 2017. El objetivo de la presente investigación fue analizar la influencia entre la comunicación organizacional y el clima organizacional, ambos identificados en un grupo de operarios, pertenecientes a una de las plantas embotelladoras de la empresa Industrias San Miguel, del rubro de consumo masivo. Asimismo, se busca identificar la relación de la comunicación formal e informal aplicada por el área de comunicaciones. La población estuvo constituida por todos los trabajadores operarios de la empresa Industrias San Miguel, cuya muestra fue 154 colaboradores, pertenecientes al género masculino. Para realizar la investigación, se utilizó una encuesta tipo lickert, diseñada en base a la matriz de operacionalización de variables. Los resultados obtenidos en la presente investigación a través del procesamiento estadístico realizado, se puede concluir lo siguiente: En los hallazgos se pudo identificar que la comunicación organizacional si tiene una influencia en el clima organizacional, debido a los resultados obtenidos en el SPSS, donde se refleja en coeficiente de Pearson de 0.648 que evidencia la influencia entre las variables. Asimismo, se determinó la efectividad de los canales de comunicación utilizados y su relación con la credibilidad y orgullo como clústers del clima organizacional.

Palabras claves: Comunicación Organizacional, Clima Organizacional, Canal formal, canal informa, credibility and pride. 


\begin{abstract}
In the present investigation it was established, by an explanatory scope, the causal relationship existing between the organizational communication and the organizational environment of the workers of Industrias San Miguel in 2017 was determined by means of an explanatory design, with a non-experimental and cross-sectional design.

The objective of the present investigation was to analyze if there is influence between the organizational communication and the organizational environment, both identified in a group of workers, belonging to one of the bottling plants of the company 'Industrias San Miguel', of the mass consumption category. Likewise, it's been tried to identify the relationship between formal and informal communication done by the corporate communication management.
\end{abstract}

The population was constituted by all the workers workers of the company Industrias San Miguel, whose sample was 154 collaborators, belonging to the masculine gender. To carry out this research, a survey was designed based on the variable's operational matrix and the Likert scale.

The results were obtained through the statistical processing performed, therefore we can conclude the following: In the findings it was possible to identify that the organizational communication does have an influence on the organizational environment, due to the results obtained in the SPSS, shown in Pearson coefficient of 0.648 .

Likewise, the effectiveness of the communication channels used and their relationship with credibility and pride as clusters of the organizational climate were determined.

Keywords: Organizational Communication, Organizational environment, formal channel, informal channel, credibility and pride. 


\section{Introducción}

En la última década, las organizaciones en nuestro país, han puesto un énfasis especial en la gestión del Talento Humano, tomando en consideración que la única diferenciación entre ellas, son precisamente las personas que las componen, a partir de ello, la búsqueda y selección de los trabajadores talentosos pasan a ser un reto, pero el verdadero desafío surge, en como retener al talento dentro de la organización, que factores debemos de considerar si queremos que ellos permanezcan en la organización. Es ahí donde se hace imperante, reconocer al clima en la organización como un factor determinante para muchos colaboradores, que hace que ellos deseen o no permanecer en las instituciones. Para ello se debe proponer políticas que contribuyan a equilibrar y balancear un clima adecuado, a través de variables como la comunicación.

Es necesario darse cuenta cuando un colaborador entiende un mensaje, el tipo de lenguaje que usa su jefe o supervisor es determinante al momento de la interrelación, de acuerdo con Gestión (2015). Una de las malas experiencias que un colaborador puede experimentar en su empresa, es que los superiores utilicen un lenguaje ofensivo. En muchas empresas se convierte en parte de la cultura. Desde el dueño hasta los colaboradores, todos disfrutan de las lisuras. "Sin embargo, esto destruye a la empresa desde dentro", comenta Kumar (2015) en un artículo publicado por LinkedIn. Fuentes periodísticas y estudios previos citados en este trabajo corroboran lo presentado por Kumar (2015) respecto al efecto de la comunicación en el clima organizacional, y desde estos estudios surge el interés por estudiar la influencia entre ambos temas. El enfoque del estudio se da en la evaluación de personal operativo, no trabajado con regularidad en investigaciones previas y que, según experiencia profesional de los autores, influye en mayor medida sobre las estrategias que aplique un área de gestión del talento humano.

Para demostrar si existe una influencia entre la comunicación y el clima organizacional, el presente trabajo se basó en datos obtenidos de una empresa de consumo masivo, Industrias San Miguel. La cual produce, distribuye y comercializa bebidas soft drink (Kola Real Agua Cielo, Generade, Fruvi, etc.) en diferentes ciudades del Perú. Industrias San Miguel, es una empresa familiar, fundada por el mayor de los hermanos Añaños (Jorge Añaños) junto con su esposa (Tania Alcázar). En la actualidad, la empresa cuenta 
con cuatro plantas de producción ubicadas en República Dominicana, Brasil y dos plantas en Perú, en Arequipa y Huacho, dirigidas cada una por los hijos de los fundadores.

Para la investigación se recogió la información en la planta de Huaura, debido a la cercanía que tenemos geográficamente y por ser la primera planta en fundarse de la empresa. La controversia surge, en cuál es la proporción o alcance de la "comunicación" dentro del clima organizacional. Para ello, se inició la investigación con la siguiente interrogante: ¿Cuál es la influencia entre la comunicación organizacional y el clima organizacional en los operarios de Industrias San Miguel en el 2017?, para ello se analizó y revisó las distintas fuentes de información secundarias, para poder determinar la presencia de distintas experiencias desarrolladas a nivel nacional e internacional, que tienen estrecha coherencia con la hipótesis y los objetivos a desarrollar en la presente investigación. Asimismo, se busca identificar la influencia entre estas variables en el corto plazo, su efecto sobre los resultados de clima organizacional anual, específicamente en los operarios de la compañía. Por ello este trabajo, agrupado en cinco capítulos trató de mostrar la influencia de dichas variables en la gestión de recursos humanos y la efectividad de los medios de comunicación usados previamente por la empresa. 


\section{Tabla de contenido}

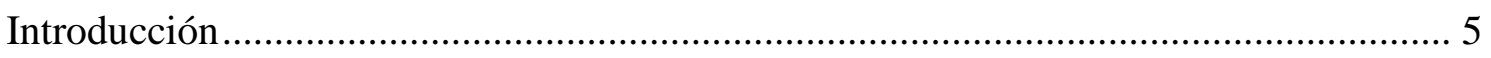

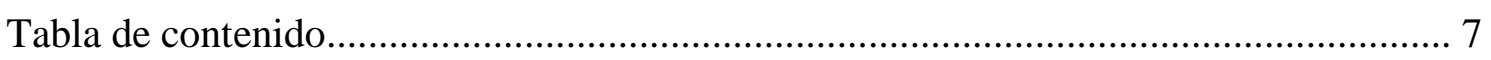

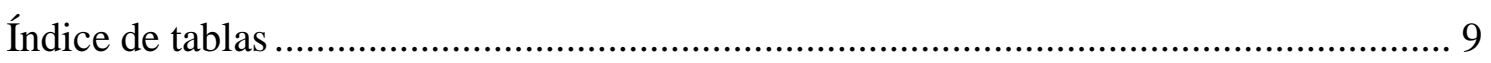

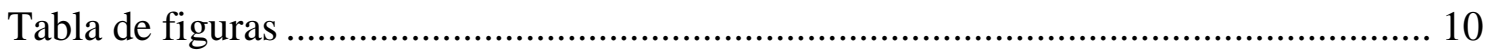

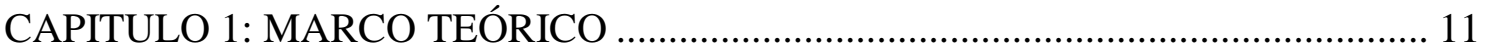

1.1. Antecedente de la investigación .............................................................. 11

1.1.1. Antecedentes internacionales ......................................................... 11

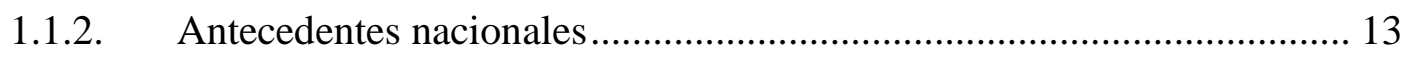

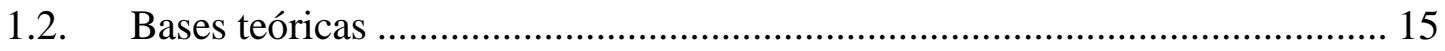

1.2.1. Comunicación Organizacional .......................................................... 15

1.2.2. Clima Organizacional ....................................................................... 20

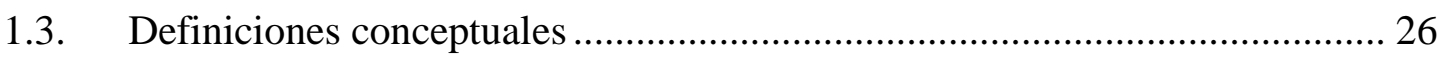

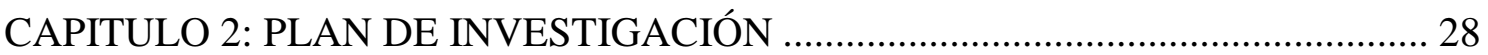

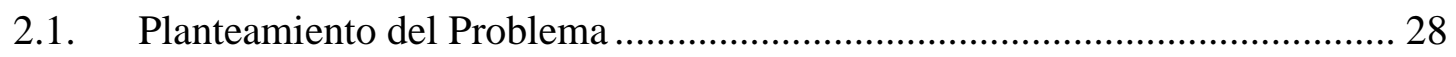

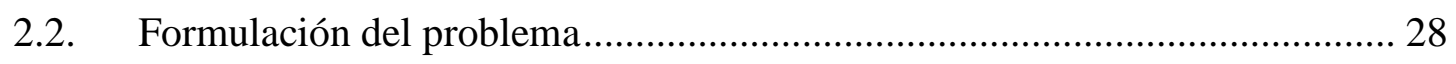

2.3. Formulación de las Hipótesis de Investigación ................................................. 29

2.4. Objetivos de la Investigación ........................................................................ 29

2.5. Justificación de la Investigación ...................................................................... 30

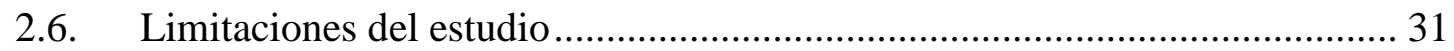

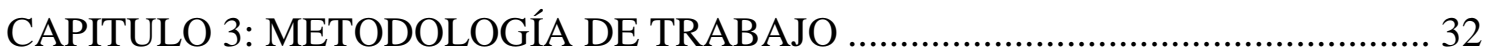

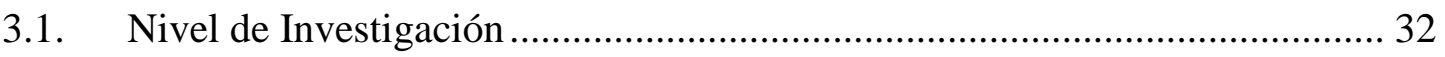

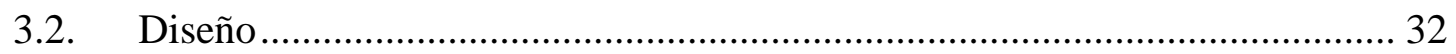

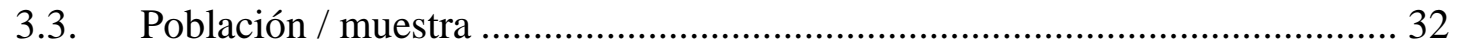

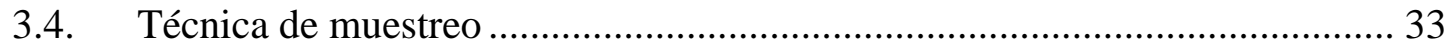

3.4.1. Criterios de inclusión de la Población objetivo: ....................................... 33

3.5. Matriz de Operacionalización de Variables....................................................... 34

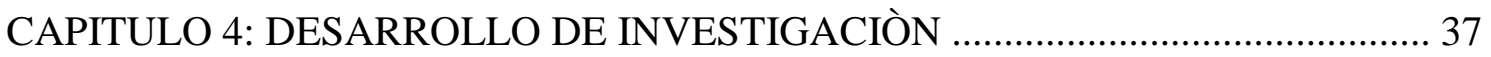

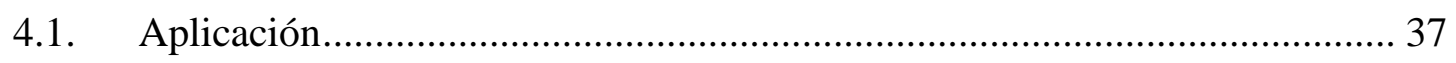

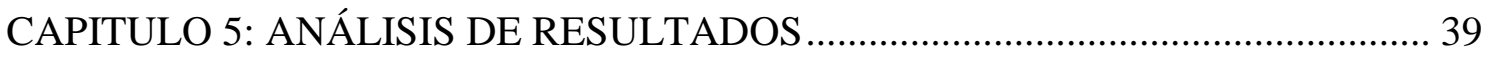

5.1. Contrastación de Hipótesis ............................................................................... 39 


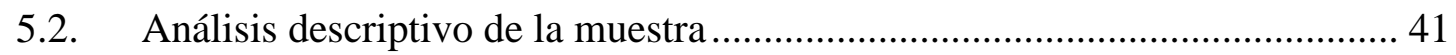

5.3. Contrastación de las hipótesis Específicas ..................................................... 43

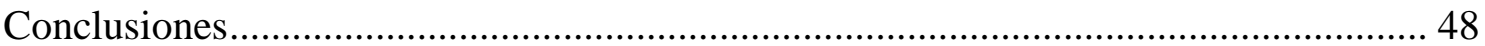

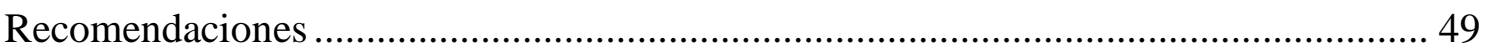

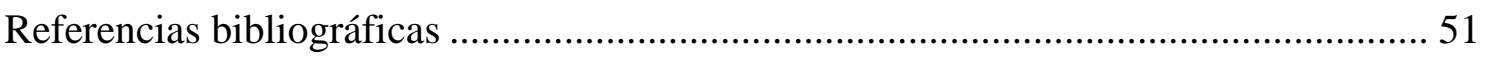

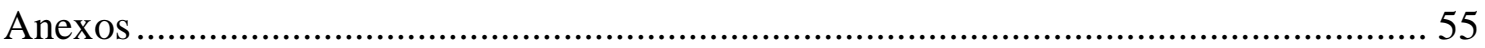




\section{Índice de tablas}

Tabla $^{\circ}$ 1: Descripción de dimensiones de acuerdo al Great Place to Work (Fuente: Great

Place to Work Institute, Inc. 2008). 23

Tabla ${ }^{\circ}$ 2: Variables e indicadores (Fuente: Elaboración propia) 34

Tabla $n^{\circ}$ 3: Cuadro de correlación de Pearson de la muestra de estudio (Fuente: Elaboración propia) 40

Tabla $\mathrm{n}^{\circ}$ 4: Cuadro de correlación de Pearson de la muestra de estudio (Fuente: Elaboración propia)

Tabla $\mathrm{n}^{\circ}$ 5: Datos descriptivos aplicados a la muestra de estudio (Fuente: Elaboración propia)

Tabla $\mathrm{n}^{\circ}$ 6: Distribución de la muestra según su rango de edad (Fuente: Elaboración propia)

Tabla $n^{\circ}$ 7: Distribución de la muestra según su área de trabajo (Fuente: Elaboración propia)....

Tabla $\mathrm{n}^{\circ}$ 8: Distribución de la muestra según su antigüedad en la empresa (Fuente: Elaboración propia) 43

Tabla $n^{\circ}$ 9: Distribución de las respuestas en la afirmación: "Existe una relación positiva entre la comunicación interna y el clima organizacional.” (Fuente: Elaboración propia) 43

Tabla $\mathrm{n}^{\circ}$ 10: Distribución de las respuestas en la afirmación: "Los empleados pueden proponer cambios en la comunicación interna para su mejora." (Fuente: Elaboración propia).....

Tabla $\mathrm{n}^{\circ}$ 11: Distribución de las respuestas según frecuencia y porcentaje de las afirmaciones 7 a 9 (Fuente: Elaboración propia)................................................. 45

Tabla ${ }^{\circ}$ 12: Encuesta (Fuente: Elaboración propia). 46 


\section{Tabla de figuras}

Figura $\mathrm{n}^{\circ}$ 1: Proceso de la comunicación. (Fuente: Extraído de Comportamiento organizacional por Robbins 2009). 16

Figura $\mathrm{n}^{\circ}$ 2: Diseño Transeccionales Correlacionales Causales (Fuente: Hernández, Fernández \& Baptista 2014) 32

Figura ${ }^{\circ}$ 3: Gráfico de dispersión de los promedios obtenidos de las encuestas realizadas (Fuente: Hernández, Fernández \& Baptista 2014) 39 


\section{CAPITULO 1: MARCO TEÓRICO}

\subsection{Antecedente de la investigación}

\subsubsection{Antecedentes internacionales}

Nuestro primer antecedente respecto a la comunicación organizacional proviene del estudio del comportamiento organizacional realizado por William Haney. En su investigación, el autor plantea que el comportamiento organizacional y la comunicación se encuentran inevitablemente entrelazados, argumenta que la comunicación es el foco de todos los modelos de interacción del ser humano, incluyendo el proceso asociado al pensamiento y el actor de transmitirlo (Haney, 1973).

De manera inicial se conoce a la comunicación como un proceso intrínseco dentro del comportamiento humano, y, por ende, a desarrollarse dentro de una organización. En 1968, Lee Thayer modifica el modelo conocido en donde una persona transmite -el emisor- un mensaje, y otra lo recibe - receptor- agregando nuevos detalles. Toma en cuenta que el mensaje es determinado por el emisor y se debe tomar en consideración las habilidades del receptor para la comprensión del mensaje. Por lo tanto, una organización no se vuelve un emisor, puesto que no tiene una consideración respecto al receptor y, sino que solo transmite el mensaje como un sistema de información (Lee, 1968).

Ya en estudios más recientes, se determinó que el objetivo principal de la comunicación organizacional es informar, diseminar y convencer a los empleados sobre los objetivos y la política de la organización. Esto puede hacerse por proporcionar una plataforma para interactuar con los empleados que trabajan en varios departamentos y gerentes de diferentes niveles, y también aumentará la motivación y la satisfacción laboral, mantendrá las operaciones de la organización y ayudará a alcanzar los objetivos de la organización (Ince y Gül, 2011).

Algunos ejemplos de investigaciones recientes encontradas son Gómez, (2007) en su investigación para su tesis doctoral, titulada La comunicación en las organizaciones para la mejora de la productividad: El uso de los medios como fuente informativa en empresas e instituciones andaluzas, tiene como objeto de estudio la comunicación en las empresas 
e instituciones y en cómo una adecuada selección, tratamiento y adecuación de la información a sus distintos miembros repercutirá en una mejora de la productividad, la eficacia y el conocimiento. El método objeto de estudio que se optó, es una herramienta metodológica como la encuesta. Se ha demostrado que teniendo un adecuado nivel de información se logra el objetivo propuesto por la organización.

Balarezo, (2014) realiza una investigación titulada "La comunicación organizacional interna y su incidencia en el desarrollo organizacional de la empresa San Miguel Drive”. El objetivo de su investigación está enfocado en la deficiente comunicación organizacional interna y en identificar de forma técnica el problema latente, sus causas y efectos. La metodología empleada tiene una explicación cualitativa, por lo que se utilizó una investigación bibliográfica y de campo. Como conclusión menciona que la comunicación organizacional influye directamente sobre la baja productividad y el desarrollo organizacional de la empresa.

Duran, (2016) por su parte, realiza un estudio donde evalúa diecisiete factores para medir clima laboral a través de la escala de Likert, aplicado por una encuesta con diferentes clústeres de conceptos. Entre ellos considera la comunicación interna y externa como una variable de alto impacto en el resultado de satisfacción laboral en su empresa de estudio los cuales confirman que pese al uso de diversos medios de comunicación (impresa y digital), la organización valoro de manera negativa la estrategia por no comunicar los temas de interés como resultados financieros, objetivos, desempeño y gestión.

Como una recomendación estratégica, Guido, (2017) en su publicación a la revista Harvard Business Deusto menciona la comunicación interna como una de las diez claves operativas para la adecuada gestión de recursos humanos. El autor lo define como un proceso continuo en que todos los colaboradores son participes y que usualmente, se ha trabajado en un departamento aislado de "comunicación corporativa" que maneja una visión más general de la empresa y no directamente, la visión del empleado que es donde suelen crearse los conflictos y malos entendidos. El autor reconoce que es un proceso complejo, no obstante, si no se alinea la estrategia corporativa con la visión del trabajador dará lugar a la creación de canales informes que trastornen la información y, en consecuencia, la percepción general del entorno laboral. 
Bustamante, (2013) realiza un estudio similar donde evalúa la comulación interna enfocada en el sector salud- como clave para el logro de objetivos de la organización, con relación a la motivación y satisfacción laboral. Los resultados de la investigación de su público objetivo demostraron un comportamiento constante entre las tres variables, y a partir de los cuales determina seis factores clave para tener resultados positivos a través de la comunicación: el papel de los líderes, comunicación cara a cara, la integración, la formación, identificación corporativa y la política de "dentro hacia fuera", donde se comienza trabajando beneficios y/o alternativas con el trabajador y su familia. Determina que estos seis factores, trabajados a través de estrategias de comunicación transparente y coherente con la cultura, aseguran motivación y excelente clima laboral.

\subsubsection{Antecedentes nacionales}

Valle (2016) realiza una investigación titulada Auditoria de la Comunicación Interna y el Clima Organizacional en una empresa industrial en Lima, en la que analiza la relación que se genera entre el resultado de una auditoría de la comunicación interna y el clima organizacional. Para esta investigación se utilizó el Cuestionario de Auditoria de la Comunicación de Varona y para medir el Clima Organizacional se utilizó el Cuestionario de Percepción de Clima Organizacional de Litwin y Stringer (1968). Con los resultados obtenidos en su investigación, comprobaron que existe una relación positiva entre ambas variables.

De la misma manera, Arica, Rojas, Iglesias y Caller (2015) en su trabajo de investigación titulado "Construcción y validación de una herramienta que mida el clima laboral y la implementación de acciones que lo favorezcan", tienen como objetivo validar una herramienta de diagnóstico de Clima Laboral. Esta información nos permitirá estar alineados a la herramienta para la recolección de datos que usaremos. La conclusión que se menciona en la investigación demuestra la importancia de definir el alcance de la herramienta y hasta dónde la alta gerencia está dispuesta a llegar para mejorar los resultados obtenidos, independientemente de que sean favorables o adversos.

Quispe (2014) en su tesis "Clima laboral y percepción de la imagen institucional en el instituto de educación superior tecnológico público "Juan Velasco Alvarado” año 2013, tiene como objeto de estudio comprobar la relación entre el clima laboral y el resultado en la percepción que tienen de la institución. En el desarrollo del trabajo, se utilizó técnica estadística del coeficiente de correlación de Pearson, logrando comprobar 
afirmativamente la hipótesis general y cada una de las hipótesis que evidencia que el clima laboral impacta significativamente en la percepción de la imagen institucional.

Jeri y Dextre (2016) es su investigación para obtener el grado de magister titulado "Maximizar el clima organizacional aplicando el endomarketing en la universidad de Ayacucho Federico Froebel", tienen como objetivo de investigación establecer la mejor estrategia para maximizar el clima laboral aplicando un plan de endomarketing. El método objeto de estudio que optaron, es una herramienta metodológica como la encuesta. Como conclusión y al procesar los resultados pudieron describir la situación real del clima organizacional e identificar un conjunto de estrategias tendientes a aprovechar y potenciar las fortalezas y a minimizar las debilidades.

Para evaluar clima laboral en general, Prado (2015) realiza una investigación de diseño correlacional a un total de 60 trabajadores administrativos de la universidad César Vallejo dividiendo clima laboral en cinco factores: condiciones laborales, comunicación, autorrealización, involucramiento laboral y supervisión. Y como segunda variable mide el desempeño laboral a través de otros cinco sub factores. Tomando en consideración que se comprobó una relación entre clima y desempeño, nos enfocamos en la percepción obtenida respecto a comunicación, como el clúster con mayor influencia sobre el desempeño de un colaborador. Dicha investigación recomienda evaluar los canales de comunicación y sus mensajes, a fin de lograr mejorar la relación con los trabajadores.

Por último, López (2016) desarrolla una investigación para su licenciatura respecto a las mismas variables que se proponen a evaluar en este trabajo: clima laboral y comunicación interna, enfocado a la gestión de la municipalidad de Chaclacayo evaluando a 156 de sus trabajadores. Su objetivo de estudio se demostró con un 63.7 \% y logro determinar que un $52 \%$ de la muestra percibe que la comunicación asertiva y operativa creará un clima laboral favorable. De igual manera, el estudio demostró que el 93\% asegura que el liderazgo transformacional era un tema preocupante y requería atención. 


\subsection{Bases teóricas}

\subsubsection{Comunicación Organizacional}

\subsubsection{Definición de Comunicación Organizacional}

De acuerdo a Robbins (2009) la comunicación está presente cerca del 70\% del tiempo que invierte una persona despierta en interactuar consigo misma y otros; y a su vez, la forma principal de interacción del ser humano para satisfacer sus necesidades sociales innatas. Para Chiavenato (2000) la comunicación implica la transferencia de información y significado de una persona a otra. Es el proceso de transmitir información y comprensión entre individuos. La manera de relacionarse con datos, ideas, valores, etc. Una transacción entre un mínimo de dos personas. Para Hellriegel y Slocum (2009) implica la capacidad de trasmitir, comprender y recibir ideas, pensamientos u otros de manera verbal o no verbal para transferir información con exactitud.

Con esta premisa, se entiende la importancia de la comunicación en la vida cotidiana, no obstante, ¿cómo se aplica en un ámbito de trabajo? Para ello, debemos entender que funciones desempeña dentro de una empresa.

\subsubsection{Funciones de la comunicación}

Robbins (2009) menciona que la comunicación cumple una función de control a través de políticas o lineamientos. Puede darse dentro de un ámbito formal, donde una directiva limita el comportamiento del individuo o informal, cuando un grupo limita a otro a través de la persuasión o hostigamiento, obligándolo a cambiar de comportamiento. Cumple también una función motivacional, pues explica a los empleados que se hace que tan bien se hace y de ser necesario, que debe hacerse para mejorar. En tercer lugar, la comunicación funciona como medio de expresión emocional para el ser humano, permitiéndole expresar emociones, percepciones y dudar a fin de satisfacer sus necesidades sociales. Por último, permite transmitir datos, informar, para la toma de decisiones y evaluación de alternativas.

Ninguna de las cuatro mencionadas es más importante que otra dentro de la misma, ya que la comunicación que tiene lugar en un grupo lleva a cabo una o más de estas funciones. No obstante, la comunicación también sigue un proceso que detallamos en el siguiente punto. 


\subsubsection{Proceso de la Comunicación y Componentes}

De acuerdo a la Figura 1, las partes del proceso de comunicación son:

Figura $\mathrm{n}^{\circ}$ 1: Proceso de la comunicación. (Fuente: Extraído de Comportamiento organizacional por Robbins 2009)

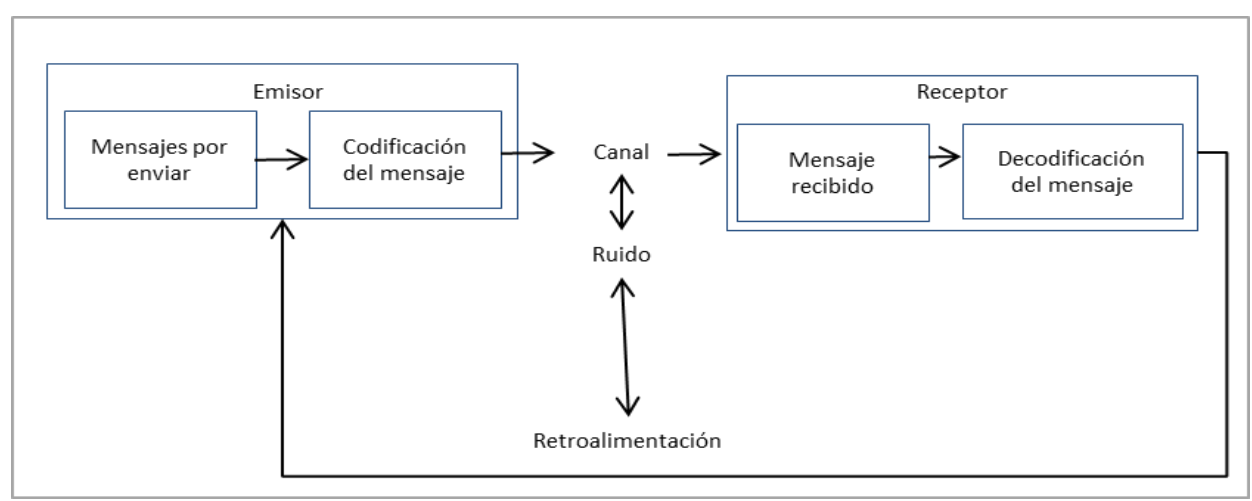

El emisor, quién inicia un mensaje al codificar un pensamiento.

El mensaje, manifestación física de la codificación del emisor. Al hablar, el habla en si misma es el mensaje; mientras que, al escribir, la escritura se convierte en el mensaje. A su vez, los ademanes con las manos o expresiones corporales forman también un mensaje.

El canal, que es el medio por el cual se transmite el mensaje. Este es a elección del emisor, quién escoge si se da por un medio formal o informal. Los canales formales son establecidos por la organización y suele relacionarse con actividades profesionales de sus miembros. Por otro lado, están los canales informales, de carácter espontaneo y surgen como respuesta a elecciones individuales.

El receptor es el objeto a quién se dirige el mensaje. No obstante, antes de recibirlo se debe traducir el mensaje para entenderlo, conocido también como decodificación. Finalmente, existe ruido alrededor del mensaje, entendido como barreras de comunicación que distorsionan el mensaje. Y finalmente, el cierre del proceso se da por la retroalimentación, la confirmación de que el mensaje se entendió con éxito.

De acuerdo a Chiavenato (2000), para que la comunicación tenga éxito no basta con que cumpla una función, sino también, debe administrar el intercambio de significados del mensaje, como: administración del tiempo - administrar la percepción del receptor para que preste atención al entorno de trabajo y permita recibir mejor la información, administrar el significado - entender los símbolos y el lenguaje a utilizar con el público 
para lograr la codificación correcta del mensaje; y administrar la confianza - crear un ambiente de confianza y apertura entre las personas, a fin de replicarlo entre toda la organización y lograr una comunicación más efectiva.

El interés de las organizaciones en la comunicación organizacional se basa en la necesidad de potenciar las habilidades de comunicación y como afecta el desempeño organizacional. Permite orientar la conducta de cada miembro y establecer relaciones personales funcionales que les permitan trabajar junto rumbo a un objetivo (Lucas, 1997).

\subsubsection{Tipos de Comunicación Organizacional}

De acuerdo a Robbins (2009), la comunicación trasmite los mensajes de un grupo a través de tres tipos de comunicación: oral, escrita y no verbal. Principalmente nos comunicamos por el medio oral con discursos, rumores y/o chismes. Permite ser veloz y obtener una retroalimentación en tiempo mínimo sobre la comprensión del mensaje.

La comunicación escrita puede darse a través de memos, cartas, correo, mensajería u otro medio que permita símbolos o palabras escritas. Usualmente es preferible como medio tangible que se transmitió un mensaje, permite realizar consultas sobre el mismo contenido enviado y hacer referencias en base al mensaje. No obstante, puede tomar mayor tiempo en realizar el mensaje antes de enviarlo a un receptor, y a retroalimentación puede no ser inmediata a diferencia de la comunicación oral.

Por último, está la comunicación no verbal, que se da cada vez que se la verbal; puede entenderse como una mirada, un gesto de manos, una expresión corporal, tono de voz u otras muestras físicas. El lenguaje corporal como también se le conoce, es un agregado a la comunicación verbal y con frecuencia agrega complejidad a la comunicación, pues no es preciso y puede o no tener un significado asociado.

Para Hellriegel y Slocum (2009) existe también la comunicación asertiva, que significa expresar con confianza lo que se siente, piensa y cree al tiempo que se respeta el punto de vista de otros. Este tipo de comunicación no es mencionado por otros autores, pues se sobreentiende como un requisito existente para mantener una comunicación eficiente y transparente entre emisor y receptor.

En el ámbito laboral por su parte, se le denomina comunicación organizacional, a toda comunicación que se da dentro de una organización. 


\subsubsection{Canales y Redes de Comunicación Organizacional}

Así como existen tipos de comunicación, también la dirección de donde nace el mensaje y el canal a utilizar. Según Chiavenato (2000), existen tres tipos de canales formales:

- La comunicación descendente, procede de la dirección o alta gerencia (el tope de la jerarquía). Se suele utilizar para transmitir instrucciones, políticas, servicios o temas de carácter obligatorio. Como, por ejemplo: lineamientos, procedimientos, políticas, instrucciones u otra información obligatoria.

- La comunicación ascendente, la cual circula desde la base de la empresa hacia arriba, suele ser el dialogo diario, un buzón de información o las encuestas de clima o satisfacción que se toman cada cierto periodo. Su objetivo es obtener información que el empleado no manifiesta en ambientes formales, pero pueden repercutir en su desempeño o el clima laboral.

- Y finalmente, se encuentra la comunicación horizontal. Este tipo se efectúa entre personas de jerarquías similares, busca la coordinación y armonía de sus miembros. Este estilo a su vez, puede replicarse entre personas de distintas jerarquías, manteniendo el sentido de igualdad.

Mientras que un canal informal, es todo aquel (no mapeado dentro de las opciones ya mencionadas) que surge de manera espontánea por elección del emisor para transmitir el mensaje y no es controlado por la organización.

Además, tenemos las redes de comunicación, definidas como un patrón de comunicación definida por el individuo (Hellriegel y Slocum, 2009).

Estas pueden ser de tres tipos la cadena, rueda y todos los canales (Robbins, 2009):

- La red de cadena sigue en forma rígida la cadena de mando formal.

- La red de rueda depende de una figura central que actúa como el conducto para todas las comunicaciones del grupo. Generalmente se da a través de un líder fuerte.

- La red de todos los canales permite que todos los miembros del grupo se comuniquen y contribuyan, sin ninguna figura de líder de por medio. 
Para esta investigación nos centraremos en la comunicación horizontal que se da por medio de canales formales e informales, y brindaremos mayor detalle respecto a la red que se trabaja dependiendo de los hallazgos encontrados.

\subsubsection{Medición de la Comunicación Organizacional}

A fin de determinar las mejores herramientas para evaluar la comunicación organizacional, nos basamos en los descubrimientos de K. Ruck y M. Welch (2012) en su artículo "Valorar la comunicación interna; gerencia y empleados perspectivas". En primer lugar, se encuentra la encuesta de la Asociación Internacional de Comunicación (Goldhaber y Rogers, 1979) cuyo enfoque integral está compuesto por ocho secciones principales. La variedad de temas de contenido está principalmente relacionada con el trabajo; pago, rendimiento, promoción, desarrollo, con solo una pregunta en el conjunto relacionada con objetivos organizacionales más amplios. Los encuestados usan una escala de Likert de cinco puntos para calificar los temas de acuerdo con la cantidad de información que se proporciona. El equilibrio entre las preguntas relacionadas con el trabajo y las preguntas relacionadas con la organización está sesgado hacia el nivel de trabajo individual y esto minimiza la importancia de la identificación organizacional. En la encuesta completa de ICA, se encuentran disponibles secciones sobre relaciones de comunicación organizacional y resultados organizacionales.

El Cuestionario de Satisfacción de Comunicación (CSQ) toma un enfoque diferente del ICA y se concentra en las dimensiones primarias de satisfacción de comunicación que incluyen: perspectiva organizacional general, integración organizacional, retroalimentación personal, relación con el supervisor, comunicación horizontalinformal, relación con subordinados, calidad de los medios, y clima de comunicación (Downs y Hazen, 1977). Proporciona información específica para un individuo y el trabajo, vinculada a la productividad, con algunos aspectos organizativos más amplios incluidos, como la claridad de la comunicación y la apertura a las ideas. Se basa en la satisfacción general más que en el volumen de información. Los hallazgos de CSQ indican que las áreas de mayor satisfacción del empleado son la comunicación de supervisión y la comunicación subordinada y el área de menor satisfacción es el factor de retroalimentación personal. Se ha encontrado que el CSQ tiene correlaciones con la satisfacción laboral. Sin embargo, tiene varias deficiencias, como la omisión de la comunicación o de nuevos medios sociales (Ruck y Welch, 2012). 
Tanto la auditoría ICA como la CSQ tienen un patrimonio creíble con sólidos procesos de desarrollo, alta confiabilidad y validez y permiten la evaluación comparativa. Son adaptables para diferentes organizaciones, aunque la gran escala del instrumento de la encuesta ICA hace que no sea práctico su uso. De estos estudios, seleccionaremos ciertos aspectos clave para utilizar en el instrumento de evaluación de este trabajo de investigación (Ruck y Welch, 2012).

\subsubsection{Clima Organizacional}

\subsubsection{Definición de Clima Organizacional}

El clima organizacional cumple un papel fundamental en estas épocas para el desarrollo de todas las organizaciones, las cuales se encuentran en un proceso continuo de mejoramiento del ambiente de trabajo a fin de tener una creciente productividad, mayor eficiencia y satisfacción por parte de sus clientes. Por consiguiente, es de gran importancia estudiar las variables ambientales que afectan dicho clima, y sus efectos sobre el desempeño personal de los trabajadores.

Hellriegel y Slocum (2009), en su libro Comportamiento Organizacional, define el clima organizacional como el proceso de evaluar el funcionamiento de la organización, departamento, equipo o puesto de trabajo, para descubrir las fuentes de problemas y con ello, detectar áreas de posible mejora. Con una evaluación de medición de clima o entrevistas abiertas, se puede identificar diferentes rasgos o actitudes de como los colaboradores se identifican con la organización y las posibles soluciones que se pueden iniciar para contrarrestar los malos resultados. Es por ello, que una de las finalidades de realizar un diagnóstico de clima organizacional en ISM es analizar la comodidad y satisfacción de los trabajadores, averiguar si existe fuentes de problema y así poder crear un programa de mejora que permite elevar los resultados obtenidos para una siguiente evaluación.

Para Chiavenato (2000), el clima organizacional se manifiesta como la influencia que existe en el ambiente de trabajo, sobre la motivación de los colaboradores, en base a la cualidad o propiedad del ambiente que perciben o experimentan sus miembros y que influye en su conducta. 
Por otro lado, Robbins (2009) menciona, que el clima organizacional es la personalidad de la organización, que se compara con diferentes grados de medición y puede asimilarse con la cultura que se tiene en cada organización. Esto permite reafirmar las tradiciones, valores, costumbres y prácticas que se desarrollan dentro de cada empresa.

Brunet (2011), define al clima organizacional como la forma en que los colaboradores perciben la realidad de la empresa. Las características personales de cada colaborador son un filtro mediante el cual los aspectos objetivos de la organización y los comportamientos de los individuos son analizados para construir la percepción del clima. El clima organizacional también es un proceso circular en el que los resultados producidos vienen a confirmar las percepciones de los empleados. Esto se refiere, a que si las características de los trabajadores, como las actitudes, percepciones, personalidad, resistencia a la presión, los valores y el nivel de aprendizaje contribuyen a la interpretación de la realidad. Así, un trabajador que adopta una actitud negativa en su trabajo debido al clima organizacional que percibe, desarrollará una actitud aún más negativa cuando vea los resultados de la organización y mucho más si la productividad es baja.

El clima Organizacional, según Vega, Arévalo, Sandoval, Aguilar \& Giraldo (2006) dentro de su libro "Panorama sobre estudios de clima organizacional en Bogotá", manifiestan que el clima organizacional describe una organización, la distingue de otras e influye en el comportamiento de las personas que la conforman. Los aspectos organizacionales que abordan son: las prácticas, políticas, liderazgo, conflictos, sistemas de recompensas y de castigos, control y supervisión, así como las particularidades del medio físico de la organización. Plantea que la influencia del clima organizacional se encuentra en las relaciones, actitudes, creencias, valores y motivaciones de las personas que trabajan en una organización. Finalmente, se propone que el clima organizacional impulsa la productividad, el sentido de pertenencia, la lealtad y la satisfacción laboral.

Salazar, Guerrero, Machado \& Cañedo (2009) en su texto mencionan que el concepto del clima organizacional implica mencionar componentes y determinantes que se consideran con frecuencia, son:

- Ambiente físico: Se refiere a la infraestructura, los equipos tecnológicos, la temperatura y el nivel de contaminación. 
- Características estructurales: Se refiere al tamaño de la organización, la estructura formal y el estilo de dirección.

- Ambiente social: Se refiere al compañerismo, los conflictos entre las áreas o colaboradores y la comunicación que se tiene en la organización.

- Características personales: Se refiere a las aptitudes y actitudes, las motivaciones y las expectativas que esperan todos los colaboradores.

- Comportamiento organizacional: Se refiere a los aspectos de productividad, ausentismo, rotación y satisfacción laboral que interpretan los colaboradores.

Lo que resulta de la interacción entre todos los componentes y determinantes manifiesta un nivel de clima organizacional dentro de una empresa

\subsubsection{Modelos de Clima Organizacional}

Litwin \& Stringer (1968) desarrollaron un cuestionario que se basa en la teoría de motivación de McCelland (1989) de carácter experimental, con el fin de identificar las percepciones que tienen los colaboradores en la organización. McClelland (1989) menciona que la motivación en los centros laborales está en relación con las necesidades de cada individuo y el predominio de alguna de éstas, tal como:

1. Poder: está constituida por la necesidad que existe en ciertas personas por el poder o de influir sobre otros y con el ejercicio de la autoridad. Y se relaciona con las siguientes dimensiones de clima organizacional según Litwin \& Stringer (1968): Estructura, Responsabilidad, Estándares.

2. Afiliación: esta necesidad es impulsada por la satisfacción de tener buenas relaciones con los demás y disfrutar de la compañía de otros. La afiliación representa en gran medida el denomino de afecto; además esta necesidad se puede ver satisfecha o insatisfecha de acuerdo a cómo se gestione las siguientes dimensiones de clima laboral, según la escala de Litwin \& Stringer (1968): Cooperación, Identidad y Relaciones.

3. Logro: cuando esta necesidad predomina, se manifiesta por la satisfacción que se obtiene al alcanzar metas y resultados. El individuo que es motivado por el logro realiza grandes esfuerzos para conseguir siempre sus objetivos y experimenta una gran satisfacción cuando los obtiene. Una fuerte necesidad de logro va acompañada de una gran insatisfacción cuando el trabajo carece de desafíos. La necesidad de logro se relaciona con las siguientes dimensiones de clima organizacional según Litwin \& Stringer (1968): Desafío, Recompensa y Conflicto.

Robbins (2009) sostiene que en la percepción del clima de una organización influyen variables tales como la estructura de la organización y su administración, las reglas y normas, la toma de decisiones, etc. Otro grupo de variables a las cuales hace referencia 
son las que intervienen directamente con el trato del personal y en ellas se incluyen las motivaciones, las actitudes, la comunicación.

Otro modelo de Clima y es comúnmente utilizado por las empresas es el modelo Great Place To Work Institute (2008), en el cual, la idea de un gran lugar para trabajar, se mide por la calidad de las tres relaciones interconectadas: La relación entre colaboradores y jefes; la relación entre los colaboradores, trabajo y empresa; así como la relación de los colaboradores entre sí. Este modelo fue certificado y se adapta mundialmente a partir del análisis y comprensión del ambiente laboral en el que se encuentre y su reconocimiento e interacción de la serie de dimensiones e indicadores que existen en cualquier lugar de trabajo. Trabaja las dimensiones de Credibilidad, respeto, trato justo, orgullo, compañerismo.

Por otro lado, un modelo interesante y que también es adecuado por cada empresa a partir de sus necesidades es el modelo Haygroup, este modelo, Hay Group es pionero y líder mundial en modelar competencias y adaptarlas a las necesidades de la empresa, tiene sus orígenes con el Dr. David McClelland, fundador del Centro McClelland dentro de Hay Group. Los modelos de competencias son únicos y reflejan la compleja realidad del clima organizacional y su impacto en el desempeño. Muestran cómo las características se interrelacionan en situaciones diversas para diferenciar el desempeño. Los modelos de competencias de Hay Group le permiten ser más flexible y más preciso en sus decisiones de selección, le ayudan a comprender las necesidades y prioridades de desarrollo y contribuyen a identificar patrones a lo largo de la carrera profesional.

\subsubsection{Medición del Clima Organizacional}

El Great Place To Work Institute (2008), esta herramienta ha desarrollado y validado mundialmente un modelo para el análisis y comprensión del ambiente laboral a partir de la construcción, reconocimiento e interacción de una serie de dimensiones que existen en cualquier lugar de trabajo, como son:

Tabla $^{\circ}$ 1: Descripción de dimensiones de acuerdo al Great Place to Work (Fuente:

Great Place to Work Institute, Inc. 2008)

\begin{tabular}{|c|l|}
\hline \multicolumn{1}{|c|}{ Dimensiones } & \multicolumn{1}{|c|}{ Descripción de cómo se manifiesten el entorno del trabajo } \\
\hline \multirow{3}{*}{ 1) Credibilidad } & La comunicación es abierta y accesible. \\
\cline { 2 - 2 } & $\begin{array}{l}\text { Hay competencia en la coordinación de los recursos humanos y } \\
\text { materiales. }\end{array}$ \\
\hline
\end{tabular}




\begin{tabular}{|c|c|}
\hline & Existe integridad y consistencia en el cumplimiento de la visión. \\
\hline \multirow{4}{*}{ 2) Respeto } & $\begin{array}{l}\text { Apoyo al desarrollo profesional y reconocimiento al esfuerzo } \\
\text { realizado. }\end{array}$ \\
\hline & $\begin{array}{l}\text { Colaboración de los empleados cuando los asuntos son } \\
\text { relevantes para ellos. }\end{array}$ \\
\hline & $\begin{array}{l}\text { Atención individualizada con los empleados respecto con sus } \\
\text { vidas personales. }\end{array}$ \\
\hline & $\begin{array}{l}\text { Lo relacionado con la vida personal de la gente: tiempo libre, } \\
\text { equilibrio entre trabajo y vida personal, interés en su por el ser } \\
\text { humano y los beneficios especiales para este. }\end{array}$ \\
\hline \multirow{3}{*}{ 3) Trato justo } & $\begin{array}{l}\text { Igualdad, trato equilibrado con todos en relación con los } \\
\text { beneficios obtenidos. }\end{array}$ \\
\hline & $\begin{array}{l}\text { Imparcialidad-no existen favoritismos al emplear y } \\
\text { promocionar. }\end{array}$ \\
\hline & $\begin{array}{l}\text { Justicia, no existe discriminación y existe proceso de } \\
\text { reclamación. }\end{array}$ \\
\hline \multirow{3}{*}{ 4) Orgullo } & En el trabajo personal y el esfuerzo individual. \\
\hline & en el trabajo hecho por el equipo o grupo de trabajo. \\
\hline & $\begin{array}{l}\text { En los productos de la organización o en la contribución a la } \\
\text { sociedad. }\end{array}$ \\
\hline \multirow{4}{*}{ 5) Compañerismo } & Camaradería \\
\hline & Posibilidad de ser tú mismo. \\
\hline & Entorno social agradable y abierto. \\
\hline & sentido de "familia" o de "equipo". \\
\hline
\end{tabular}

Dentro de estas dimensiones, se considera a la empresa como un lugar donde los colaboradores sienten confianza entre las personas con las que trabajan y están orgullosos del trabajo que realizan. Esta es la idea de un gran lugar para trabajar, que se mide por la calidad de las tres relaciones interconectadas: La relación entre colaboradores y jefes; la relación entre los colaboradores, trabajo y empresa; así como la relación de los colaboradores entre sí.

Existen diversos instrumentos para medir el clima en una organización. Todos ellos realizan la medición por dimensiones, es decir, las características a ser medidas. Algunos de los instrumentos más utilizados para medir el clima son el OCQ (Organizacional Climate Questionnaire), Litwin, G. y Stringer, R. (1968). Este cuestionario mide nueve dimensiones:

1. Estructura. Se refiere al sentimiento que tienen los colaboradores respecto de las restricciones, el número de reglas, controles y procedimientos que existen. 
2. Responsabilidad. Se refiere al sentimiento por parte de los colaboradores de "ser su propio jefe". Poder tomar las decisiones y no tener que consultar cada paso con los superiores.

3. Recompensa. Se refiere al sentimiento de ser recompensado por el trabajo bien hecho.

4. Riesgo. Se refiere al sentido de desafío en el trabajo y en la organización.

5. Calidez. Se refiere a la percepción de una buena confraternidad general.

6. Apoyo. Se refiere a la percepción de la ayuda mutua entre todos los colaboradores de la organización.

7. Normas. Se refiere a la percepción de la importancia de las normas y exigencias en el rendimiento en el trabajo.

8. Conflicto. Se refiere al sentimiento que los directivos presten atención a las opiniones, aunque éstas sean divergentes de su punto de vista.

9. Identidad. Se refiere al sentimiento de pertenecer a una empresa y ser un miembro valioso dentro de ella y de un grupo de trabajo específico.

Por otro lado, otra de las investigaciones realizada por Chiang, Núñez, Martín \& Salazar (2010), donde se analiza la relación entre compromiso y clima laboral según género y edad. Después de analizar los resultados, se muestra que no existen diferencias importantes entre ambos géneros ni al momento de segmentar por edad. Uno de los resultados muestra que las mujeres están presionadas por el deber y los hombres, si se sienten reconocidos, aumentan su compromiso afectivo. Sin embargo, los niveles de compromiso y de clima organizacional son similares para ambos géneros.

\subsubsection{Dimensiones de Clima Organizacional}

Las dimensiones que se describen son las características que se aprecian y pueden ser medidas y que influyen en el comportamiento de los individuos dentro de una organización. Por esta razón, para llevar a cabo un diagnóstico de clima organizacional es conveniente conocer las dimensiones que serán abordadas en la presente investigación, por la naturaleza de la misma) que fueron tomadas a partir del sistema Great Place to Work Institute (2008). Las cuales son:

Credibilidad: Es como el colaborador percibe a sus superiores y a la empresa. Se genera mayor credibilidad si atendemos y desarrollamos las siguientes competencias:

- Comunicación: Generando información completa y transparente de la empresa para los colaboradores. Incentivar la accesibilidad a los directivos.

- Capacidad: Desarrollando la competencia de los líderes en su visión y manejo del negocio, así como la coordinación de los recursos. 
- Integridad: Asegurando la confiabilidad y consistencia de los directivos, así como el manejo ético del negocio.

- Orgullo: Es cuando hay un valor por el trabajo, cuando nos sentimos parte de una compañía con una buena imagen en la comunidad. Se genera más orgullo si atendemos y desarrollamos las siguientes competencias:

- Orgullo del trabajo: Generando el sentimiento de que el trabajo realizado tiene un significado especial y adiciona valor a la empresa.

- Orgullo del equipo: enalteciendo los logros de equipo. Creando un ambiente de orgullo por la contribución de los integrantes de un equipo a metas y objetivos.

- Orgullo de empresa: Desarrollando la imagen de la empresa frente a sus colaboradores. Impulsando la contribución a la comunidad.

Se identificó estas dimensiones, debido que, en la actualidad, la empresa, ya desarrolla una medición de clima organizacional, y las dimensiones mencionadas son parte de la medición.

Finalmente, con respecto a la medición de Clima Organizacional en el Perú, se utilizan modelos basados en el Great Place to Work y el modelo de Haygroup, adaptados a cada una de las realidades de las empresas.

\subsection{Definiciones conceptuales}

- Comunicación organizacional: La comunicación implica la transferencia de información y significado de una persona a otra. Es el proceso de transmitir información y comprensión entre individuos. La manera de relacionarse con datos, ideas, valores, etc. (Chiavenato, 2000).

- Clima organizacional: Según Litwin \& Stringer (1968) el concepto del clima organizacional son los efectos subjetivos, que se perciben dentro de una organización, así como otros factores importantes como: las actitudes, creencias, valores y motivación de las personas que trabajan en una organización dada.

- Comunicación formal: Referencia a comunicarse a través de un canal para transmitir un mensaje establecido por la organización y que transmite información relacionada a ella (Robbins, 2009). 
- Comunicación informal: Referencia a comunicarse a través de un canal para transmitir un mensaje espontaneo y surge como respuesta a decisiones individuales (Robbins, 2009).

- Credibilidad: Según el Great Place to Work Institute (2008), es como el colaborador percibe a sus superiores y a la empresa.

- Orgullo: Según el Great Place to Work Institute (2008), es cuando hay un valor por el trabajo, cuando nos sentimos parte de una compañía con una buena imagen en la comunidad. 


\section{CAPITULO 2: PLAN DE INVESTIGACIÓN}

\subsection{Planteamiento del Problema}

En la actualidad somos conscientes de que las empresas se preocupan cada vez más porque el colaborador este y se sienta bien dentro de las organizaciones, por ello existe una clara tendencia de estas a buscar estrategias que puedan contribuir a ello, estamos habituados a trabajar con todo tipo de personas, la diversidad en las empresas es cada vez mayor, pues estamos en mundo globalizado, sin embargo existe un grupo de colaboradores a los que por la naturaleza de su actividad no se les exige mayor grado de instrucción dado que sus actividades son operativas y esto obliga a las empresas a generar estrategias particulares de comunicación que permitan una comunicación directa, fluida, con un lenguaje de fácil comprensión.

Ante la marcada tendencia por ganar presencia en el mercado como una empresa reconocida por su buen clima organizacional a través de prácticas de comunicación transparente, Industrias San Miguel, está interesada en saber si realmente la estrategia de comunicación que utilizan con este grupo de colaboradores está contribuyendo con que ellos se sientan bien al realizar sus actividades y si comprenden la importancia de su labor frente a las estrategias de la empresa.

Por ello la presente investigación busca demostrar la influencia existente entre la comunicación organizacional y el clima organizacional, con el fin de proveer información práctica y relevante para gestores de gestión humana y/o comunicación corporativa al momento de plantear estrategias para sus áreas para los próximos años.

\subsection{Formulación del problema}

Problema General:

¿Cuál es la influencia de la comunicación organizacional en el clima organizacional de los operarios de Industrias San Miguel en el 2017?

Problema Específico 1: 
¿Cómo afecta la comunicación interna en el clima organizacional de los operarios de Industrias San Miguel en el 2017?

Problema Específico 2:

¿Cuál es el impacto de la red de comunicación formal en el clima organizacional de los operarios de industrias San Miguel en el 2017?

Problema Especifico 3:

¿Cuál es el impacto de la red de comunicación informal en el clima organizacional de los operarios de industrias San Miguel en el 2017?

\subsection{Formulación de las Hipótesis de Investigación}

Hipótesis General:

La comunicación organizacional influye significativamente en el clima organizacional de los operarios de Industrias San Miguel en el 2017

Hipótesis Específica 1:

La comunicación interna afecta positivamente en el clima organizacional de los operarios de Industrias San Miguel en el 2017

Hipótesis Especifica 2:

La red de comunicación formal impacta positivamente en el clima organizacional de los operarios de industrias San Miguel en el 2017

Hipótesis Especifica 3:

La red de comunicación informal impacta positivamente en el clima organizacional de los operarios de industrias San Miguel en el 2017

\subsection{Objetivos de la Investigación}

Objetivo General:

Determinar la influencia significativa de la comunicación organizacional en el clima organizacional de los operarios de Industrias San Miguel en el 2017 


\section{Objetivo Especifico 1:}

Analizar el efecto de la comunicación interna en el clima organizacional de los operarios de Industrias San Miguel en el 2017

Objetivo Especifico 2:

Conocer cómo impacta la red de comunicación formal en el clima organizacional de los operarios de industrias San Miguel en el 2017

\section{Objetivo Especifico 3:}

Conocer cómo impacta la red de comunicación informal en el clima organizacional de los operarios de industrias San Miguel en el 2017

\subsection{Justificación de la Investigación}

La presente investigación en el ámbito practico, servirá como punto de inicio para interiorizar una estrategia de las áreas de comunicaciones y gestión humana de la empresa Industrias San Miguel, para la evaluación de clima organizacional para futuros años. Los resultados obtenidos demostraran las preferencias de los operarios para recibir información y así recomendar la aplicación de estrategias para su difusión. También, podremos obtener resultados en base a los años de antigüedad con respecto al orgullo y sentido de pertenencia hacia la empresa, además, se obtendrán resultados de la percepción de operarios sobre sus jefes. Lo mencionado, nos servirá para poder informar a la empresa de mecanismos para revertir o potenciar los resultados obtenidos.

La información teórica trabajada en esta investigación es sólida y rigurosa pues presenta antecedentes y bibliografía actualizada de fuentes académicas confiables, lo que hace que a partir de ella se conozca la medición de las variables y los instrumentos más utilizados en este tema de investigación, por lo que contribuirá también con futuras investigaciones donde se trabajen las variables Comunicación Organizacional y Clima organizacional con una población diferencial al comúnmente desarrollado es decir dirigido hacia los trabajadores operarios. 


\subsection{Limitaciones del estudio}

Una de las limitaciones que se nos presentaron durante la presente investigación fue la distancia de la planta de Industrias San Miguel, que se ubica en la ciudad de Huacho, a tres horas de lima, donde se encuentran todos los operarios que son nuestra población a encuestar.

En cuanto a limitación en la información brindada por la empresa, no tenemos ninguna complicación en acceder a las evaluaciones realizadas por ISM de manera interna, no obstante, no existe mucha información referente de estudios similares para equipos operarios en la industria local o extranjera sobre los cuales podamos comparar objetivos y/o resultados.

Cabe mencionar que el proyecto presenta limitaciones en resultados por ser una muestra de personal operario, dentro de un período de tiempo específico y con características predefinidas por su manejo de la comunicación y la gestión en gestión del talento, debido a que se mantiene como una empresa familiar y los parámetros se siguen guiando en base a lo que se diga por parte de gerencia general y directorio, que son los dueños de la compañía. 


\section{CAPITULO 3: METODOLOGÍA DE TRABAJO}

\subsection{Nivel de Investigación}

Esta investigación es aplicada, presenta un alcance explicativo, es de base no experimental con un enfoque cuantitativo, es explicativo porque busca conocer la relación causal existe entre dos o más variables en un determinado contexto. (Hernández, Fernández \& Baptista, 2010, p. 84).

\subsection{Diseño}

El diseño de la investigación que se utilizó en el presente trabajo es no-experimental de corte transversal con diseño Transeccionales Correlacionales Causales pues se recogerá la información en un solo momento (Hernández, Fernández \& Baptista, 2014, p.157).

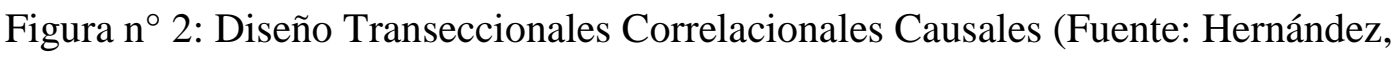

Fernández \& Baptista 2014)

\begin{tabular}{|} 
Correlacionales-causales \\
Se recolectan datos y se describe relación \\
$\left(X_{1}-Y_{1}\right)$ \\
Se recolectan datos y se describe relación \\
$\left(X_{2}-Y_{2}\right)$ \\
Se recolectan datos y se describe relación \\
$\left(X_{k}-Y_{k}\right)$
\end{tabular}

\subsection{Población / muestra}

La población estará conformada por todos los colaboradores de la empresa Industrias San Miguel de la planta ubicada en la provincia de Huaura, que consta de 255 trabajadores. Para esta investigación se tendrá como muestra a un total de 154 operarios, quienes serán el objeto de la investigación. 


\subsection{Técnica de muestreo}

El tamaño de la muestra ha sido obtenido mediante criterios no probabilísticos de muestreo intencional, por razones de acceso y disponibilidad. La muestra está constituida por todos los operarios de Industrias San Miguel, que son 154 colaboradores.

\subsubsection{Criterios de inclusión de la Población objetivo:}

Todos los trabajadores operarios con mínimo seis meses de antigüedad, además de ello, la muestra es totalmente masculina.

El tamaño de la muestra es 154 encuestas. Con las siguientes características:

Margen de error:

$5 \%$

Nivel de Confianza:

$95 \%$

Población:

255 colaboradores

Fórmula para obtener la muestra:

$$
n=\frac{N * Z_{\propto}{ }^{2} p * q}{d^{2} *(N-1)+Z^{2}{ }_{\alpha} * p * q}
$$

Donde:

$\mathrm{n}=$ Tamaño de la muestra

$\mathrm{Z}_{\propto}=1.96$ al cuadrado

$\mathrm{p}=$ proporción esperada $($ en este caso $5 \%=0.05)$

$\mathrm{q}=1-\mathrm{p}($ en este caso $1-0.05=0.95)$

$\mathrm{d}=$ precisión (en su investigación use un 5\%)

$$
n=\frac{255 * 1.96^{2} * 0.05 * 0.95}{0.05^{2}(255-1)+1.96^{2} * 0.05 * 0.95}=154
$$

Se realizarán 154 encuestas como muestra para este estudio. 


\subsection{Matriz de Operacionalización de Variables}

Tabla n $^{\circ}$ 2: Variables e indicadores (Fuente: Elaboración propia) 


\begin{tabular}{|c|c|c|c|c|}
\hline \multicolumn{5}{|c|}{ VARIABLES E INDICADORES } \\
\hline \multicolumn{5}{|c|}{ Variable 1: COMUNICACIÓN ORGANIZACIONAL } \\
\hline Dimensiones & Indicadores & Ítems & $\begin{array}{l}\text { Escala de } \\
\text { medición }\end{array}$ & Niveles o rangos \\
\hline $\begin{array}{l}\text { Comunicación } \\
\text { Interna }\end{array}$ & $\begin{array}{l}\text { Percepción } \\
\text { general }\end{array}$ & $\begin{array}{l}\text { 1. Existe una relación positiva entre la comunicación interna y el clima } \\
\text { organizacional. } \\
\text { 2. Los empleados pueden proponer cambios en la comunicación interna para } \\
\text { su mejora. }\end{array}$ & \multirow{5}{*}{$\begin{array}{l}\text { (5) Siempre } \\
\text { (4) Casi Siempre } \\
\text { (3) A veces } \\
\text { (2) Casi Nunca } \\
\text { (1) Nunca }\end{array}$} & \multirow{5}{*}{$\begin{array}{l}\text { Bajo (1-2) } \\
\text { Moderado (3-4) } \\
\text { Alto (5) }\end{array}$} \\
\hline \multirow{3}{*}{$\begin{array}{l}\text { Canal } \\
\text { Informal }\end{array}$} & \multirow{3}{*}{ Efectividad } & $\begin{array}{l}\text { 3. Tengo una comunicación frecuente con mi jefe directo. } \\
\text { 4. La comunicación informal (boca a boca) es positiva para el desarrollo del } \\
\text { clima organizacional. }\end{array}$ & & \\
\hline & & 5. Las conversaciones informales influyen en la toma de decisiones. & & \\
\hline & & 6. La comunicación informal brinda suficiente información. & & \\
\hline Canal Formal & Efectividad & $\begin{array}{l}\text { 7. La comunicación formal (comunicados y/o presentaciones corporativas) } \\
\text { satisface las necesidades de información. } \\
\text { 8. La comunicación por medio digitales (correos y redes sociales) son } \\
\text { efectivos para transmitir información. } \\
\text { 9. Prefiero la información publicada en los murales en lugar de redes sociales } \\
\text { y/o correos. }\end{array}$ & & \\
\hline
\end{tabular}




\begin{tabular}{|c|c|c|c|c|}
\hline \multicolumn{5}{|c|}{ Variable 2: CLIMA ORGANIZACIONAL } \\
\hline Dimensiones & Indicadores & Ítems & $\begin{array}{c}\text { Escala de } \\
\text { valores }\end{array}$ & Niveles o rangos \\
\hline \multirow{6}{*}{ Credibilidad } & \multirow{6}{*}{ Capacidad } & 10. Mi jefe es accesible, es fácil hablar con él. & \multirow{11}{*}{$\begin{array}{l}\text { (5) Siempre } \\
\text { (4) Casi Siempre } \\
\text { (3) A veces } \\
\text { (2) Casi Nunca } \\
\text { (1) Nunca }\end{array}$} & \multirow{11}{*}{$\begin{array}{l}\text { Bajo (1-2) } \\
\text { Moderado (3-4) } \\
\text { Alto (5) }\end{array}$} \\
\hline & & 11. Mi jefe me mantiene informado acerca de cosas y cambios importantes. & & \\
\hline & & $\begin{array}{l}\text { 12. Mi jefe muestra aprecio y reconocimiento por el buen trabajo y por el } \\
\text { esfuerzo extra. }\end{array}$ & & \\
\hline & & $\begin{array}{l}\text { 13. Mi jefe involucra a las personas en decisiones que afectan el trabajo o el } \\
\text { ambiente de trabajo de éstas. }\end{array}$ & & \\
\hline & & 14. Mi jefe demuestra un interés sincero en mí como persona, no sólo como & & \\
\hline & & empleado. & & \\
\hline \multirow{5}{*}{ Orgullo } & \multirow{5}{*}{$\begin{array}{l}\text { Orgullo del } \\
\text { equipo }\end{array}$} & $\begin{array}{l}\text { 15. Aquí se propicia que las personas equilibren su vida de trabajo y su vida } \\
\text { personal. }\end{array}$ & & \\
\hline & & $\begin{array}{l}\text { 16. Siento que mi participación es importante y que hace una diferencia en } \\
\text { la organización. }\end{array}$ & & \\
\hline & & 17. Cuando veo lo que logramos, siento una sensación de orgullo. & & \\
\hline & & 18. A las personas les gusta venir a trabajar. & & \\
\hline & & 19. Estoy orgulloso de decir a otros que trabajo aquí. & & \\
\hline
\end{tabular}




\section{CAPITULO 4: DESARROLLO DE INVESTIGACIÒN}

\subsection{Aplicación}

El objetivo es analizar la influencia de la comunicación organizacional y sus efectos en el clima organizacional de los operarios de industrias San Miguel en el año 2017.

Técnicas de Recolección de datos

Los datos fueron recolectados mediante la aplicación de una encuesta elaborada para la presente investigación que recoge información sobre la comunicación (formal e informal) así como también el clima organizacional a través de dos dimensiones: credibilidad y orgullo. Las encuestas se aplicaron de manera personal, formato impreso en el plazo de 15 días.

En la presente investigación se realizó el análisis para confirmar la veracidad, se usó el valor Alfa de Cronbach para medir la consistencia interna de las escalas de comunicación organizacional. El valor Alfa de Cronbach es de $\alpha=0.7 .20$ un valor alto que demuestra que la escala es fiable. Por otro lado, el valor Alfa de Cronbach para clima organizacional es de $\alpha=0.78$ un valor alto que demuestra que la escala es fiable, recordemos que el valor alfa es positivo toda vez se dé la cercanía a 1.

Para los fines de determinar la validez del instrumento se recurrió a la opinión de los expertos. Por otro lado, se sometió a prueba piloto la compresión de los ítems a los trabajadores operarios, seleccionando lo más representativo para obtener escalas reducidas en número de preguntas.

Como se ha mencionado en el capítulo anterior, se han considerado a todos los colaboradores en el área de operaciones que tengan como mínimo 6 meses en la compañía.

Técnicas de procesamiento, análisis e interpretación de la información 
El cuestionario se aplicó personalmente a 154 trabajadores, de operaciones, de la empresa Industrias San miguel. El llenado de cada encuesta tomo un promedio de 10 minutos por persona. La tabulación, verificación y procesamiento de la información se realizó con un procesador dual Core y IBM SPSS Stadistics 24. Se utilizaron los análisis estadísticos descriptivos como media, promedio, desviación estándar, frecuencia y porcentajes en las diferentes secciones de la encuesta 


\section{CAPITULO 5: ANÁLISIS DE RESULTADOS}

\subsection{Contrastación de Hipótesis}

Para esta investigación se utilizó el coeficiente de Pearson, debido a que ambas variables son de intervalo y poseen una distribución normal. Las variables son:

$\mathrm{X}=$ Promedio de evaluación de las preguntas relacionadas a comunicación organizacional.

$\mathrm{Y}=$ Promedio de evaluación de las preguntas relacionadas a clima organizacional.

A fin de comprobar la distribución normal de los datos se realizó un gráfico de dispersión (Figura 1) y la prueba Kolmogorov de Smirnov (Tabla 2) sobre los resultados por parte de la muestra.

Figura $n^{\circ}$ 3: Gráfico de dispersión de los promedios obtenidos de las encuestas realizadas (Fuente: Hernández, Fernández \& Baptista 2014)

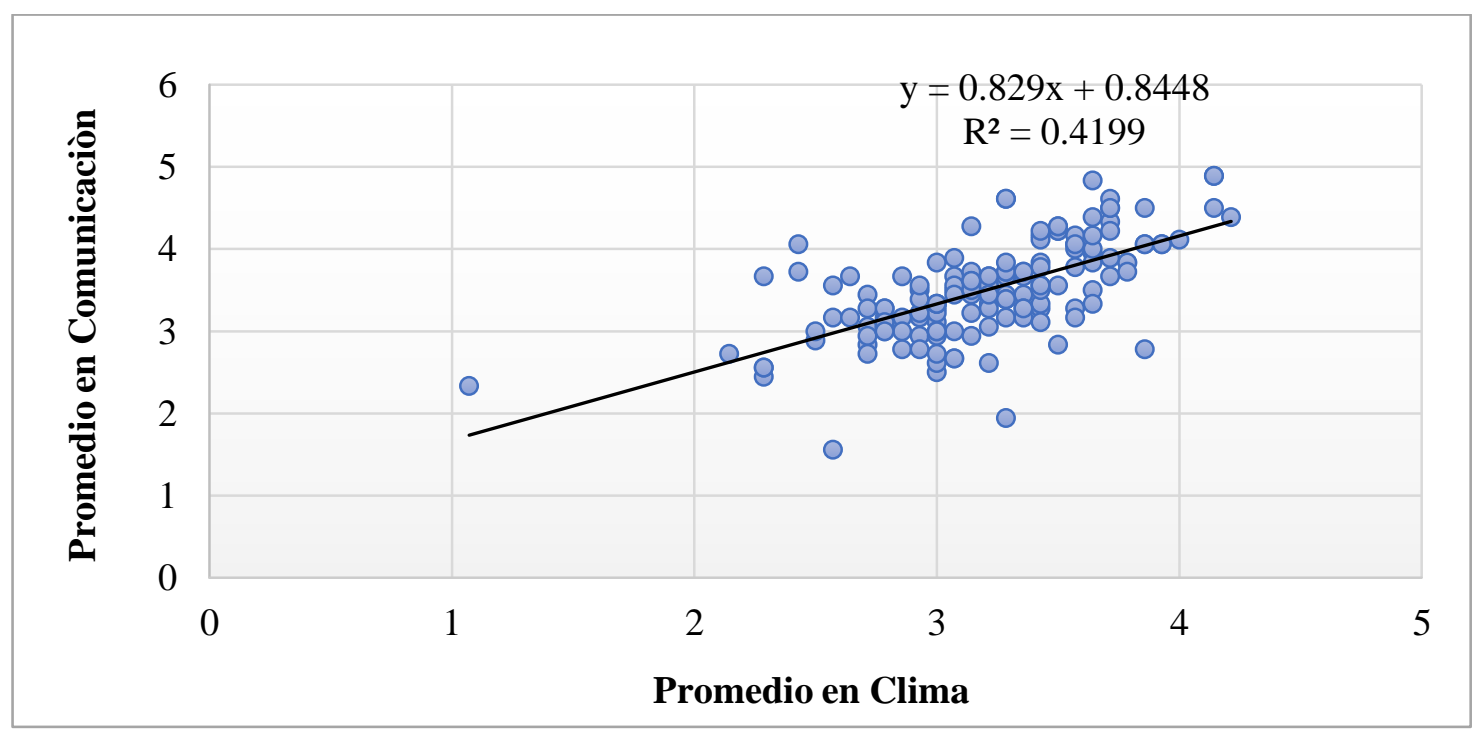

Como se observa en la Figura 3, los datos tienen una distribución normal con tendencia positiva. 
Tabla ${ }^{\circ}$ 3: Cuadro de correlación de Pearson de la muestra de estudio (Fuente:

Elaboración propia)

\begin{tabular}{|l|r|c|c|r|r|r|}
\hline & \multicolumn{3}{|c|}{ Kolmogorov-Smirnov } & \multicolumn{3}{c|}{ Shapiro-Wilk } \\
\cline { 2 - 7 } & Estadístico & gl & Sig. & Estadístico & gl & Sig. \\
\hline $\begin{array}{l}\text { Promedio } \\
\text { comunicación }\end{array}$ &, 064 & 154 &, $200^{*}$ &, 969 & 154 &, 002 \\
$\begin{array}{l}\text { Promedio } \\
\text { clima }\end{array}$ &, 057 & 154 &, $200^{*}$ &, 991 & 154 &, 440 \\
\hline
\end{tabular}

*. Esto es un límite inferior de la significación verdadera.

a. Corrección de significación de Lilliefors

Nota. Cuadro de elaboración propia, con los datos obtenidos en base al análisis de encuestas a través del programa SPSS.

En la Tabla 3 se comprueba que el valor de la prueba es mayor a 0. Por lo que tiene una distribución normal como la comparada en el gráfico de distribución previo.

Contrastación de la hipótesis general

$\mathrm{H}_{0}=$ La comunicación organizacional no influye significativamente en el clima organizacional de los operarios de Industrias San Miguel en el 2017

$\mathrm{H}_{1}=\mathrm{La}$ comunicación organizacional influye significativamente en el clima organizacional de los operarios de Industrias San Miguel en el 2017

Para realizar la comprobación de nuestra hipótesis se utilizará el estadístico de prueba de Pearson. Dependiendo del resultado de la correlación "r", el resultado podría ser:

Cercano a 0: Se sobreentiende que no existe correlación entre las variables.

Cercano a 1 o -1: Existe una correlación. Si "r" es negativo (-) entonces existe correlación inversa. De ser positiva (+), existe correlación directa. Es decir, tiene influencia en la variable dependiente. 
Tabla ${ }^{\circ}$ 4: Cuadro de correlación de Pearson de la muestra de estudio (Fuente:

Elaboración propia)

\begin{tabular}{|c|c|c|c|}
\hline & & $\begin{array}{l}\text { Promedio } \\
\text { comunicación }\end{array}$ & $\begin{array}{l}\text { Promedio } \\
\text { clima }\end{array}$ \\
\hline \multirow[t]{3}{*}{$\begin{array}{l}\text { Promedio } \\
\text { comunicación }\end{array}$} & $\begin{array}{l}\text { Correlación } \\
\text { de Pearson }\end{array}$ & 1 & $648^{+-}$ \\
\hline & $\begin{array}{l}\text { Sig. } \\
\text { (bilateral) }\end{array}$ & &, 000 \\
\hline & $\mathrm{N}$ & 154 & 154 \\
\hline \multirow[t]{3}{*}{$\begin{array}{l}\text { Promedio } \\
\text { clima }\end{array}$} & $\begin{array}{l}\text { Correlación } \\
\text { de Pearson }\end{array}$ & $648^{--}$ & 1 \\
\hline & $\begin{array}{l}\text { Sig. } \\
\text { (bilateral) }\end{array}$ &, 000 & \\
\hline & $\mathrm{N}$ & 154 & 154 \\
\hline
\end{tabular}

Nota: Cuadro de elaboración propia, con los datos obtenidos en base al análisis de encuestas a través del programa SPSS.

Los resultados apreciados en la Tabla 4 muestran que el coeficiente de influencia entre ambas variables es $0,648^{* *}$, lo cual se transcribe como una correlación directa moderada entre la comunicación organizacional y el clima organizacional de la empresa. La hipótesis Ho es rechazada. Es decir, La comunicación organizacional influye significativamente en el clima organizacional de los operarios de Industrias San Miguel en el 2017.

\subsection{Análisis descriptivo de la muestra}

A continuación, se presentará una breve descripción de los resultados estadísticos obtenidos de la muestra de operarios.

Según se observa en la Tabla 4 la muestra del estudio está conformada por 154 empleados encuestados, respecto a 19 preguntas. Como parte del mismo cuestionario, se obtuvieron tres datos descriptivos sobre la muestra para comparar resultados:

Tabla $n^{\circ}$ 5: Datos descriptivos aplicados a la muestra de estudio (Fuente: Elaboración propia)

\begin{tabular}{|c|l|l|l|}
\hline Valor & \multicolumn{1}{|c|}{ Edad } & \multicolumn{1}{c|}{ Área de trabajo } & \multicolumn{1}{c|}{ Antigüedad } \\
\hline $\mathbf{1}$ & 19 a 29 años & Logística & $0-3$ años \\
\hline $\mathbf{2}$ & 30 a 39 años & Mantenimiento & $>3$ años a 6 años \\
\hline $\mathbf{3}$ & 40 a 49 años & Producción & $>6$ años a 9 años \\
\hline
\end{tabular}




\begin{tabular}{l|l|l|l|}
4 & 50 años a más & Sostenibilidad & $>9$ años a 13 años
\end{tabular}

El valor otorgado del 1 al 4 brinda facilidad para procesar los datos. En base a ello, la muestra tuvo las siguientes características:

Tabla $n^{\circ}$ 6: Distribución de la muestra según su rango de edad (Fuente: Elaboración propia)

\begin{tabular}{|ll|r|r|}
\hline & Frecuencia & Porcentaje \\
\hline Válido & 19 a 29 años & 45 & 29,2 \\
& 30 a 39 años & 67 & 43,5 \\
40 a 49 años & 35 & 22,7 \\
50 años a más & 7 & 4,5 \\
Total & 154 & 100,0 \\
\hline
\end{tabular}

Nota: Los datos son obtenidos en base al análisis de encuestas a través del programa SPSS.

La muestra evaluada se ha distribuido en un $66.2 \%$ entre $30-49$ años de edad. Casi un $30 \%$ pertenece al grupo de edad más joven de la compañía entre los 19-29 años.

Tabla n 7: Distribución de la muestra según su área de trabajo (Fuente: Elaboración propia)

\begin{tabular}{|ll|r|r|r|r|}
\hline & Frecuencia & Porcentaje & $\begin{array}{c}\text { Porcentaje } \\
\text { válido }\end{array}$ & $\begin{array}{r}\text { Porcentaje } \\
\text { acumulado }\end{array}$ \\
\hline Válido & Logistica & 9 & 5,8 & 5,8 & 5,8 \\
& Mantenimiento & 71 & 7,1 & 7,1 & 13,0 \\
Producción & 128 & 83,1 & 83,1 & 96,1 \\
Sostenibilidad & 6 & 3,9 & 3,9 & 100,0 \\
Total & 154 & 100,0 & 100,0 & \\
\hline
\end{tabular}

Nota. Los datos son obtenidos en base al análisis de encuestas a través del programa SPSS.

La planta de Huara se divide en las cuatro áreas mencionadas en la Tabla 7 para la gerencia de operaciones, entre esas áreas el $83.1 \%$, es decir mayoría absoluta, pertenecen al área de producción de la compañía. Esta distribución es coherente con la distribución del número de trabajadores de la empresa, de entre los 255 colaboradores, el 59\% pertenece a esta área. 
Tabla $n^{\circ}$ 8: Distribución de la muestra según su antigüedad en la empresa (Fuente:

Elaboración propia)

\begin{tabular}{|c|c|c|c|c|c|}
\hline & & Frecuencia & Porcentaje & $\begin{array}{l}\text { Porcentaje } \\
\text { válido }\end{array}$ & $\begin{array}{l}\text { Porcentaje } \\
\text { acumulado }\end{array}$ \\
\hline \multirow[t]{5}{*}{ Válido } & 0 a 3 años & 61 & 39,6 & 39,6 & 39,6 \\
\hline & $>3$ años a 6 & 7 & 4,5 & 4,5 & 44,2 \\
\hline & $>6$ años a 9 & 15 & 9,7 & 9,7 & 53,9 \\
\hline & $>9$ años & 71 & 46,1 & 46,1 & 100,0 \\
\hline & Total & 154 & 100,0 & 100,0 & \\
\hline
\end{tabular}

Nota. Los datos son obtenidos en base al análisis de encuestas a través del programa SPSS.

En relación a la antigüedad, el $60.4 \%$ presenta una antigüedad mayor a los 3 años de relación laboral con Industrias San Miguel. Dato importante al considerar su experiencia como empleados en relación al clima y la comunicación organizacional en la empresa.

\subsection{Contrastación de las hipótesis Específicas}

Hipótesis Específica 1: La comunicación interna afecta positivamente en el clima organizacional de los operarios de Industrias San Miguel en el 2017

Para probar esta hipótesis, se plantearon las siguientes dos afirmaciones:

- Existe una relación positiva entre la comunicación interna y el clima organizacional.

- Los empleados pueden proponer cambios en la comunicación interna para su mejora.

La primera afirmación nos permite visualizar si la muestra considera la relación como existente, mientras que la segunda, conocer si los colaboradores forman parte de las estrategias de comunicación dentro de la empresa.

Mientras mayor sea el nivel de propuestas en la comunicación interna, la apreciación del clima debería ser más alta.

Los resultados obtenidos fueron:

Tabla n 9: Distribución de las respuestas en la afirmación: "Existe una relación positiva entre la comunicación interna y el clima organizacional." (Fuente: Elaboración propia) 


\begin{tabular}{|c|c|c|c|}
\hline & & Frecuencia & Porcentaje \\
\hline \multirow[t]{6}{*}{ Válido } & Nunca & 7 & 4,5 \\
\hline & Casi Nunca & 21 & 13,6 \\
\hline & A veces & 64 & 41,6 \\
\hline & Casi Siempre & 46 & 29,9 \\
\hline & Siempre & 16 & 10,4 \\
\hline & Total & 154 & 100,0 \\
\hline
\end{tabular}

Nota: Los datos son obtenidos en base al análisis de encuestas a través del programa SPSS.

El $18.1 \%$ de muestra (los que marcaron Nunca y Casi nunca) manifestó que no considera que exista una relación positiva entre la comunicación interna y el clima organizacional. No obstante, un 71.5\% (los que marcaron A veces y Casi Siempre) considera que lo contrario si ocurre. Es decir, que mientras se tenga un buen nivel de comunicación interna, el clima organizacional mejorará dentro de la empresa.

Tabla $n^{\circ}$ 10: Distribución de las respuestas en la afirmación: "Los empleados pueden proponer cambios en la comunicación interna para su mejora.” (Fuente: Elaboración propia)

\begin{tabular}{|cl|r|r|}
\hline & Frecuencia & Porcentaje \\
\hline Válido & Nunca & 10 & 6,5 \\
& Casi Nunca & 37 & 24,0 \\
A veces & 80 & 51,9 \\
Casi Siempre & 19 & 12,3 \\
Siempre & 8 & 5,2 \\
Total & 154 & 100,0 \\
\hline
\end{tabular}

Nota. Los datos son obtenidos en base al análisis de encuestas a través del programa SPSS.

Por otro lado, al ser consultados sobre su participación en la comunicación interna, el 64.2\% (los que marcaron A veces y Casi Siempre) considera que tiene una participación moderada. Lo que demuestra cierto poder de decisión sobre las estrategias de comunicación interna que se aplican en esta organización.

Con ambos datos, podemos afirmar la primera sub hipótesis, que la comunicación interna, si afecta positivamente en el clima organizacional de los operarios de Industrias San Miguel en el 2017, ya que los resultados de la encuesta realizada muestran un $71.5 \%$ de apreciación de los operarios. 
Hipótesis Específica 2: La red de comunicación formal impacta positivamente en el clima organizacional de los operarios de industrias San Miguel en el 2017.

Para probar esta hipótesis, se plantearon las siguientes preguntas (7 y 8 respectivamente):

- La comunicación formal (comunicados y/o presentaciones corporativas) satisface las necesidades de información.

- La comunicación por medios digitales (correos y redes sociales) son efectivos para transmitir información.

Tabla $\mathrm{n}^{\circ}$ 11: Distribución de las respuestas según frecuencia y porcentaje de las afirmaciones 7 a 9 (Fuente: Elaboración propia)

\begin{tabular}{|l|r|r|r|r|}
\cline { 2 - 5 } \multicolumn{1}{c|}{} & \multicolumn{2}{c|}{ Pregunta 7 } & \multicolumn{2}{c|}{ Pregunta 8 } \\
\hline & \multicolumn{1}{c|}{$\mathrm{F}$} & \multicolumn{1}{c|}{ F } & \multicolumn{1}{c|}{$\%$} \\
\hline Nunca & 19 & $12 \%$ & 8 & $5 \%$ \\
Casi Nunca & 45 & $29 \%$ & 22 & $14 \%$ \\
A veces & 52 & $34 \%$ & 55 & $36 \%$ \\
Casi Siempre & 29 & $19 \%$ & 53 & $34 \%$ \\
Siempre & 9 & $6 \%$ & 16 & $10 \%$ \\
\hline Total & 154 & $100 \%$ & 154 & $100 \%$ \\
\hline
\end{tabular}

En la distribución, se puede inferir lo siguiente:

- La red de comunicación formal (pregunta 7) tiene un nivel moderado-bajo de aceptación del 53\% en los operarios (los que respondieron A veces y Casi Siempre). También, podemos observar que solo el $6 \%$ lo considera totalmente efectivo.

- La comunicación por medios digitales (pregunta 8) tiene un nivel moderado de $70 \%$ (los que respondieron A veces y Casi Siempre) de aceptación para transmitir la información.

Al contrastar la hipótesis sobre la red de comunicación por canal formal impacta positivamente en el clima organizacional, podemos confirmar que la hipótesis es rechazada por la muestra. Los resultados obtenidos del 53\% de aceptación, reflejan que la red de comunicación formal no impacta positivamente en el clima organizacional, debido a que no les brinda mayor nivel de información en los operarios, ni satisface su necesidad de información. 
Hipótesis Específica 3: La red de comunicación informal impacta positivamente en el clima organizacional de los operarios de industrias San Miguel en el 2017

Para probar esta hipótesis, se plantearon las siguientes preguntas (4, 6 y 9 respectivamente):

- La comunicación informal es positiva para el desarrollo del clima organizacional.

- La comunicación informal brinda suficiente información.

- $\quad$ Prefiero la información publicada en los murales en lugar de redes sociales y/o correos.

Tabla $n^{\circ}$ 12: Encuesta (Fuente: Elaboración propia)

\begin{tabular}{|l|r|r|r|r|r|r|}
\cline { 2 - 7 } \multicolumn{1}{c|}{} & \multicolumn{2}{c|}{ Pregunta 4 } & \multicolumn{2}{c|}{ Pregunta 6 } & \multicolumn{2}{c|}{ Pregunta 9 } \\
\hline & $\mathrm{F}$ & $\%$ & $\mathrm{~F}$ & $\%$ & $\mathrm{~F}$ & $\%$ \\
\hline Nunca & 6 & $4 \%$ & 4 & $3 \%$ & 7 & $5 \%$ \\
Casi Nunca & 14 & $9 \%$ & 11 & $7 \%$ & 15 & $10 \%$ \\
A veces & 70 & $45 \%$ & 45 & $29 \%$ & 55 & $36 \%$ \\
Casi Siempre & 47 & $31 \%$ & 71 & $46 \%$ & 51 & $33 \%$ \\
Siempre & 17 & $11 \%$ & 23 & $15 \%$ & 26 & $17 \%$ \\
\hline Total & 154 & $100 \%$ & 154 & $100 \%$ & 154 & $100 \%$ \\
\hline
\end{tabular}

En la distribución que tenemos, se puede inferir lo siguiente:

- La comunicación por canal informal es aceptada como positiva (pregunta 4) por los encuestados en un 76\% (los que marcaron A veces y Casi siempre) a un nivel moderado a alto.

- La comunicación por canal informal, con los resultados de la muestra, si brinda suficiente información a los colaboradores (pregunta 5), ya que tiene un nivel moderado a alto de información a un $75 \%$ (los que marcaron A veces y Casi siempre).

- Al consultar por la información en los murales (pregunta 9), se obtuvo que un 69\% (los que contestaron A veces y Casi Siempre) lo considera importante para obtener información.

$\mathrm{Al}$ responder la hipótesis sobre si la red de comunicación informal impacta positivamente en el clima organizacional, podemos confirmar que la hipótesis es aceptada por la muestra. Los resultados obtenidos del $76 \%$ de aceptación, reflejan que la red de 
comunicación informal impacta positivamente en el clima organizacional, debido que los colaboradores los consideran positivo a diferencia de la comunicación formal que tiene la empresa. Además, el 75\% de los encuestados menciona que les brinda información suficiente y satisface su necesidad de información. 


\section{Conclusiones}

Al analizar los resultados obtenidos en la presente investigación a través del procesamiento estadístico realizado, se concluye que:

La hipótesis general es confirmada, pues de acuerdo con los resultados obtenidos (Tabla No. 3) el coeficiente de relación $r$ de Pearson es $0,648^{* *}$, es decir existe una relación de influencia moderada entre la comunicación organizacional y el clima organizacional en Industrias San Miguel 2017. Es decir, si la comunicación organizacional cambia afectará directamente el clima organizacional de un equipo, de acuerdo al $r$ de Pearson encontrado y los estudios previos mencionados en los antecedentes que afirman lo mismo.

La primera hipótesis especifica es confirmada la $\mathrm{r}$ de Pearson es 0,58 lo que quiere decir que, existe una relación directa y de influencia positiva entre la comunicación interna y el clima organizacional dentro de los equipos de operarios de Industrias San Miguel.

La segunda hipótesis específica es confirmada, aunque con una moderación baja la $\mathrm{r}$ de Pearson es 0,498 lo que quiere decir que la red de comunicación formal, tiene una influencia de baja a moderada en el clima organizacional de los operarios. Los resultados obtenidos del 53\% de aceptación, reflejan que la red de comunicación formal no impacta positivamente en el clima organizacional de los operarios, debido a que no les brinda un adecuado nivel de información o es su preferencia. Para la muestra, los métodos que se aplican por la empresa como correos y presentaciones formales no son efectivos.

La tercera hipótesis especifica es confirmada la $\mathrm{r}$ de Pearson es 0,58 lo que quiere decir que, la red de comunicación informal tiene un impacto directo y positivo. se identificó que los colaboradores prefieren este canal de comunicación, evidenciado en el $76 \%$ de aceptación en los resultados de la encuesta. Esto ocurre, porque el 75\% de los encuestados menciona que les brinda información suficiente y satisface su necesidad de información. Es efectivo para ellos. 


\section{Recomendaciones}

Al encontrar efectivamente que existe relación entre la comunicación organizacional y el clima organizacional en los colaboradores operarios, se recomienda:

Especificar la estrategia de comunicación sobre el personal operario a través de un análisis de efectividad sobre las acciones de comunicación que se realizan en el año. De acuerdo a los resultados de efectividad demostrados por cada canal (formal e informal) se denota que las necesidades de información no están siendo atendidas de manera satisfactoria.

Se recomienda que las estrategias de comunicación en la organización deben ser difundidas a través de los murales, réplicas con grupos pequeños a través de representantes del área de comunicación o recursos humanos, reuniones de cinco minutos al inicio de la jornada de trabajo, material impreso para cada trabajador o voceros como otras alternativas a un canal formal. Asimismo, los colaboradores deben ser parte de la creación del contenido que se transmite al resto de sus compañeros. Puede utilizarse también como canal formal la comunicación horizontal, pues tipo se efectúa entre personas de jerarquías similares, busca la coordinación y armonía de sus miembros. Este estilo a su vez puede replicarse entre personas de distintas jerarquías, manteniendo el sentido de igualdad. la retransmisión de la información a través de los líderes hacia sus equipos, a fin de asegurar la réplica de información clave reforzando la comunicación horizontal que ya existe entre el grupo de operarios.

Respecto a la efectividad del canal formal, la muestra demostró estar poco satisfecha con el nivel de información. Esto mismo puede deberse a las características de la muestra y métodos aplicados (correos y reuniones informativas), puesto que no todo el personal tiene un correo asociado a la compañía a través del cual obtener información y por sus jornadas, tampoco pueden asistir a la totalidad de las reuniones informativas sin perjudicar la producción. Se recomienda ajustar el canal formal a través de otras opciones que sean controladas por el área de comunicaciones como se hace referencia en el párrafo anterior, y actualizar la data con los correos institucionales de todos los colaboradores operarios. 
Se recomienda brindar capacitación para los líderes, orientadas a reforzar la comunicación, y que los líderes de cada equipo puedan ser a su vez voceros de los objetivos de la empresa para sus equipos. Pues para el canal informal, es preferente la conversación entre un grupo de igual jerarquía, lo cual se observa en el grupo operario de la muestra, que pasa jornadas completas, reforzar su comunicación a un ambiente asertivo, con líderes que generen compromiso y orgullo por sus equipos, refuerza los lazos entre sus miembros y crea un clima de confianza mutua. 


\section{Referencias bibliográficas}

Arica Rodríguez, L. \& Rojas García, K. \& Iglesias Curto, D. \& Caller Chuecas, M. (2015) Construcción y validación de una herramienta que mida el clima laboral y la implementación de acciones que lo favorezcan. (Trabajo aplicativo de post grado, Universidad Peruana de Ciencias Aplicadas, Facultad de Negocios. Lima, Perú).

Balarezo, B. (2014). "La comunicación organizacional interna y su incidencia en el desarrollo organizacional de la empresa San Miguel Drive." Universidad técnica de Ambato- Ecuador

Brunet, L. (2011). El clima de trabajo en las organizaciones: Definición, diagnóstico y consecuencia. México: Trillas

Bustamante, E. (2013). El clima de comunicación, la motivación y la satisfacción laboral en un proceso de atención primaria en Colombia. Revista de Comunicación y Salud. Vol. 3, no 1, p. 35-49. [Consulta: 14 de mayo de 2018]

Chiang, M., Nuñez, A., Martín, M. \& Salazar, M. (2010). Compromiso del trabajador hacia su organización y la relación con el Clima Organizacional: Análisis de género y edad. Panorama Socioeconómico. 40, 92-103 (ISNN 0718-1566).

Chiavenato, I. (2000). Administración de Recursos Humanos. México: McGraw Hill.

Downs, Cal W. y Hazen, M. (1977) A factor Analytic Study of Communication Satisfaction. International Journal of Business Communication, volumen 14 (3), 63-73. doi: $10.1177 / 002194367701400306$

Duran Silva, C. \& Zenteno Hidalgo, A. (2016) Factores y prácticas de alto desempeño que influyen en el clima laboral. (Tesis para optar por el grado de Magíster, Facultad de Ingeniería. Concepción, Argentina). Recuperado de http://www.scielo.org.co/pdf/inno/v26n59/v26n59a10.pdf [Consulta: 15 de mayo de 2018] 
Gestión.pe (11 de febrero de 2015, como se cita en Kumar, 2015) ¿Qué hacer cuando se usa lenguaje ofensivo en el centro de trabajo? (http://gestion.pe/empleomanagement/que-hacer-cuando-se-usa-lenguaje-ofensivo-centro-trabajo-2123168)

Goldhbaber, Gerald M. y Rogers, D. (1979) Auditing organizational communication systems: the ICA commmunication audit. Michigan, Estados Unidos: Kendall/Hunt Pub. Co

Gómez Aguilar, M. (2007). La comunicación en las organizaciones para la mejora de la productividad: El uso de los medios como fuente informativa en empresas e instituciones andaluzas. (Tesis para optar por el grado de Doctor, Facultad de Periodismo. Universidad de Málaga. $\quad$ Málaga, España). Recuperado de http://www.biblioteca.uma.es/bbldoc/tesisuma/17672697.pdf [Consulta: 17 de mayo de 2018]

Great place to work. Encuesta de clima organizacional. Recuperado de http://www.greatplacetowork.com.pe/ [Consulta: 17 de mayo de 2018]

Guido, S. \& Cervantes, A. \& Cuadrado, M. (2017) Las políticas de recursos humanos: claves operativas para una correcta gestión de personas. (Artículo de la revista Harvard Business Review Deusto). [Consulta: 18 de mayo de 2018]

Haney, William. (Ed.). (1992) Commuication and Organizational Behavior: Text and Cases. Pensilvania, Estados Unidos: Richard D. Irwin.

Hellriegel, D., y Slocum, J. (2009). Comportamiento Organizacional. México D.F.: Cengage Learning.

Hernández, R; Fernández, C. \& Baptista, P (2014) Metodología de la Investigación. Sexta edición. Mexico: McGraw-Hill Interamericana Editores

Ince, M. \& Gül, H. (2011). The Role of the Organizational Communication on Employees' Perception of Justice: A Sample of Public Institution from Turkey. European Journal of Social Sciences. Vol. 21 (1).

Jeri Lagos, L.E. \& Dextre Vilcapoma, M.G. (2016) Maximizar el clima organizacional aplicando el endomarketing en la universidad de Ayacucho Federico Froebel. (Tesis de 
maestría, Universidad Peruana de Ciencias Aplicadas, Facultad de Negocios. Lima, Perú).

Lee, O. Thayer (Ed.). (1968) Comunication and Comunication Systems in organizations, management and interpersonal relations. Winsconsin, Estados Unidos: Richard D. Irwin.

Litwin, G. y Stringer, R. (1968): Motivation and organizational Environment. Cambridge, Mass.: Harvard University Press.

López Quevedo, K. (2016) Influencia de la comunicación interna en el nivel de clima organizacional de la municipalidad de Chaclacayo. (Tesis de licenciatura, Facultad de Comunicaciones, Universidad Peruana Unión. Lima, Perú). Recuperado de http://repositorio.upeu.edu.pe/handle/UPEU/583 [Consulta: 18 de mayo de 2018]

López, P. (2014). Comunicación interna, medir es crecer. Portal de Recursos humanos. Recuperado de http://www.infocapitalhumano.pe/recursoshumanos/articulos/comunicacion-interna-ci-medir-es-crecer/ [Consulta: 22 de mayo de 2018]

McClelland, D. (1989) Estudio de Motivación Humana. España: Editorial Narcea.

Pérez, R. (2014, como se cita en Materan, 2014; Allen y Meyer, 1990). Motivación y Compromiso Organizacional en Personal Administrativo de Universidades Limeñas. PUCP: Facultad de Letras y Ciencias Humanas.

Prado Álvarez, C. (2015) Relación entre el clima laboral y desempeño laboral en los trabajadores administrativos de la universidad César Vallejo de Trujillo. (Tesis de maestría, Facultad de Ingeniería, Universidad Nacional de Trujillo. La Libertad, Perú). Recuperado de http://dspace.unitru.edu.pe/bitstream/handle/UNITRU/2651/TESIS\%20MAESTRIA\%2 0CYNTTIA\%20GISELL\%20PRADO\%20ALVAREZ.pdf?sequence=1\&isAllowed=y [Consulta: 22 de mayo de 2018]

Quispe, D. (2014). Clima Laboral y percepción de la imagen institucional en el instituto de educación superior tecnológico público "Juan Velasco Alvarado”. (Tesis de doctorado, Facultad de Educación, Universidad San Martin de Porres. Lima, Perú). Recuperado de 
http://www.repositorioacademico.usmp.edu.pe/bitstream/usmp/682/3/quispe_d.pdf [Consulta: 22 de mayo de 2018]

Real Academia Española. Recuperado de http://dle.rae.es/?id=HXFDqkJ [Consulta: 24 de mayo de 2018]

Robbins, S. (2009). Comportamiento Organizacional. Decimotercera Edición. México: Pearson Education

Ruck, Kevin y Welch, Mary (2012). Valuing internal communication; management and employee perspectives. Public Relations Review, volumen 38 (2), 294-302. doi: 10.1016/j.pubrev.2011.12.016

Salazar, J., Guerrero, J., Yadira Bárbara Machado, Y. \& Cañedo, R. (2009) Clima y cultura organizacional: dos componentes esenciales en la productividad laboral.

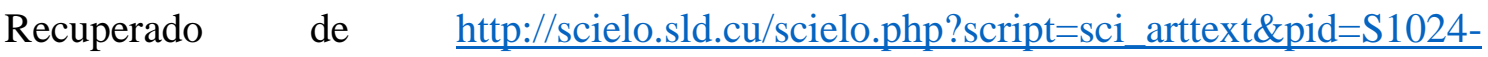
94352009001000004 [Consulta: 18 de mayo de 2018]

Valle Cruzado, C. (2016) Auditoría de la comunicación interna y el clima organizacional de una empresa industrial de Lima. (Tesis de licenciatura inédita, Universidad Peruana de Ciencias Aplicadas, Facultad de Psicología. Lima, Perú).

Vega, D., Arévalo, A., Sandoval, J., Aguilar, M.C. \& Giraldo, J. (2006). Panorama sobre los estudios de clima organizacional en Bogotá, Colombia (1994-2005). Diversitas: Perspectivas en Psicología., 2(2), 329-349 (ISSN 1794-9998). 


\section{Anexos}

Anexo 1: Instrumento Aplicado en esta investigación

Estamos realizando una investigación sobre la relación existente entre comunicación y clima organizacional en la empresa. Por ello, recurrimos a ustedes para confirmar si las siguientes afirmaciones son correctas. Favor de marcar en la temporalidad que se ajuste mejor según el enunciado.

Edad:

19 años a 29 años

30 años a 39 años

40 años a 50 años

50 años a más

\section{Área de trabajo:}

Logística

Mantenimiento

Producción

Sostenibilidad

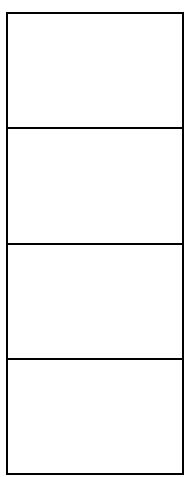

0-3 años

$>3$ años a 6 años

>6 años a 9 años

>9 años a 13 años

\section{Antigüedad en la empresa:}

$>3$ años a 6 años
$>6$ años a 9 años
$>9$ años a 13 años
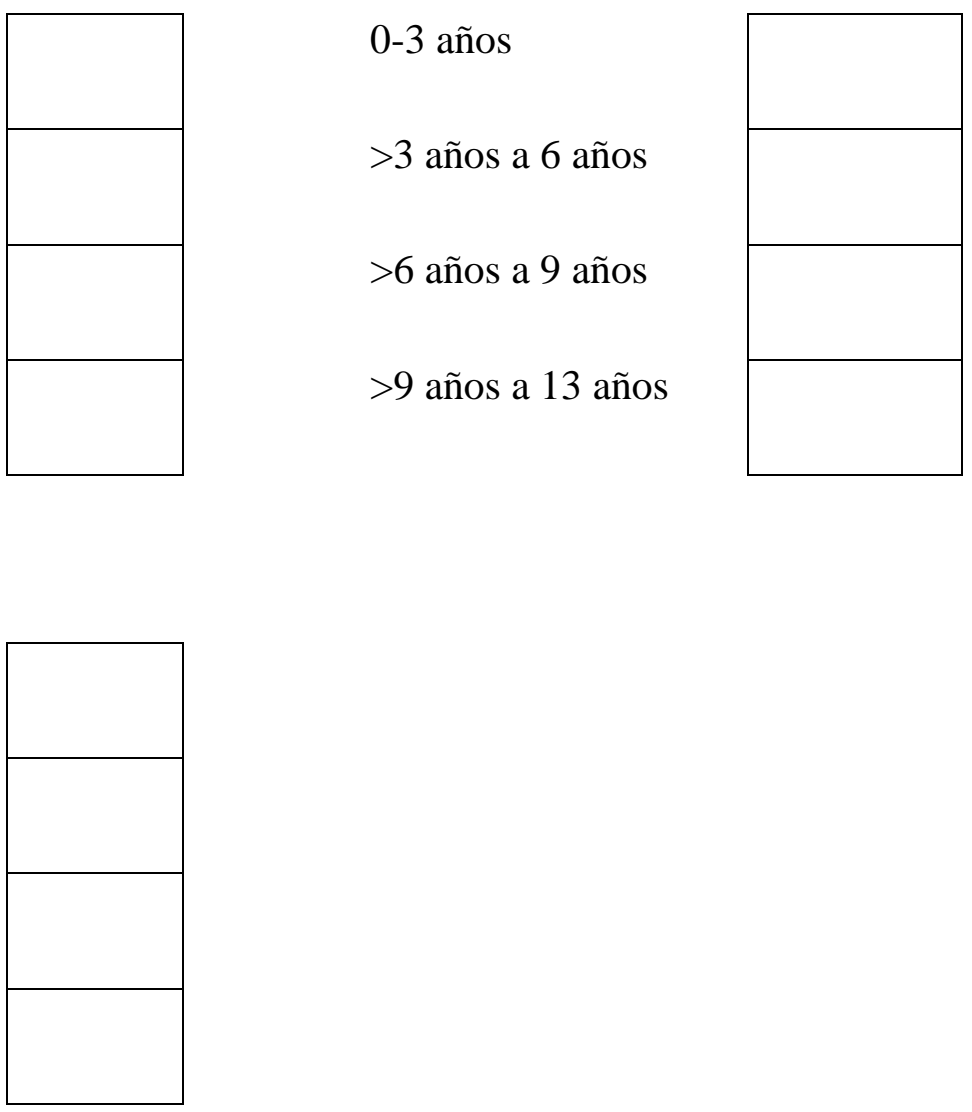

\begin{tabular}{|c|c|c|c|c|c|l|}
\hline No. & ÍTEMS & NUNCA & CASI & A & CASI & SIEMPRE \\
\end{tabular}




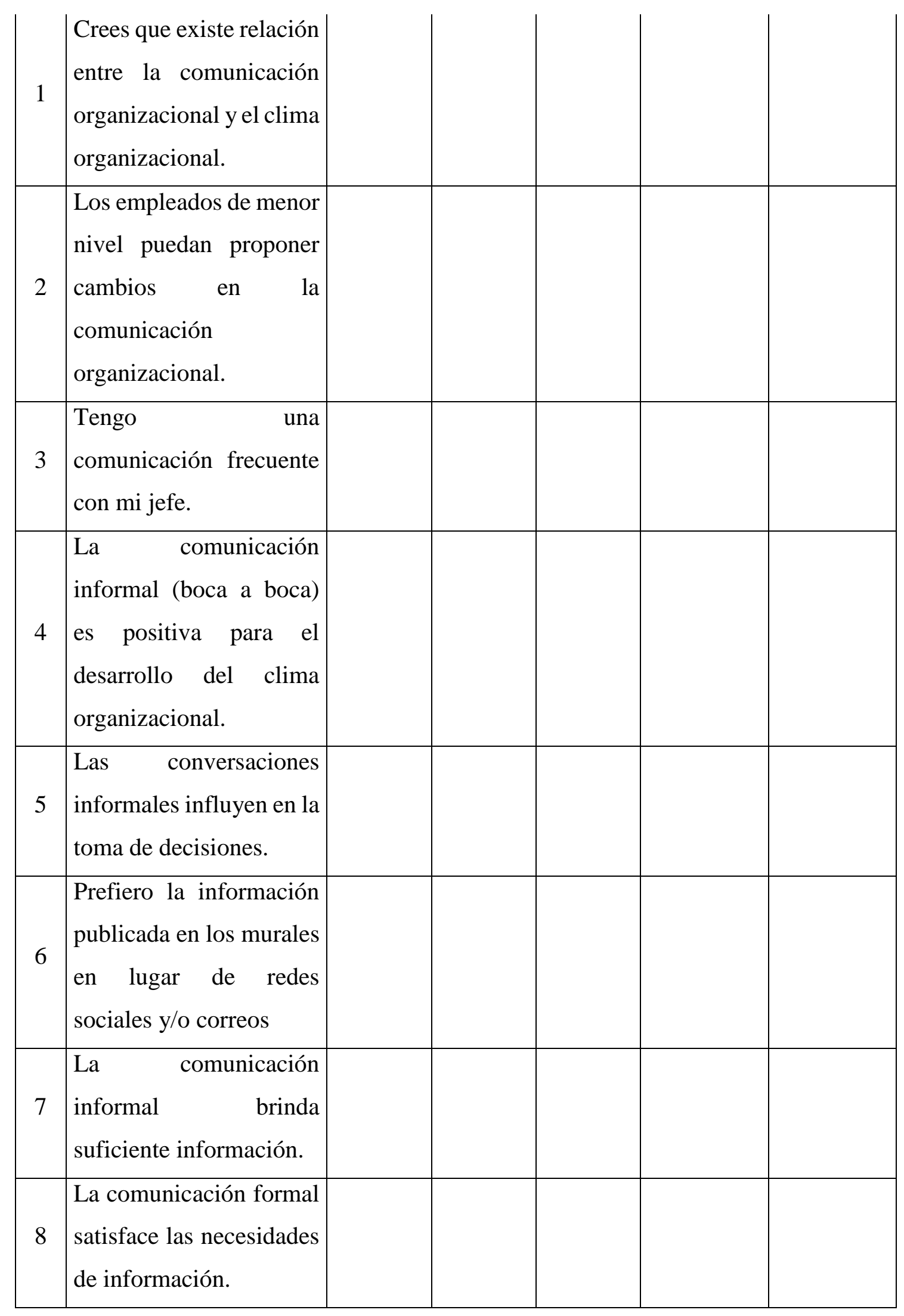




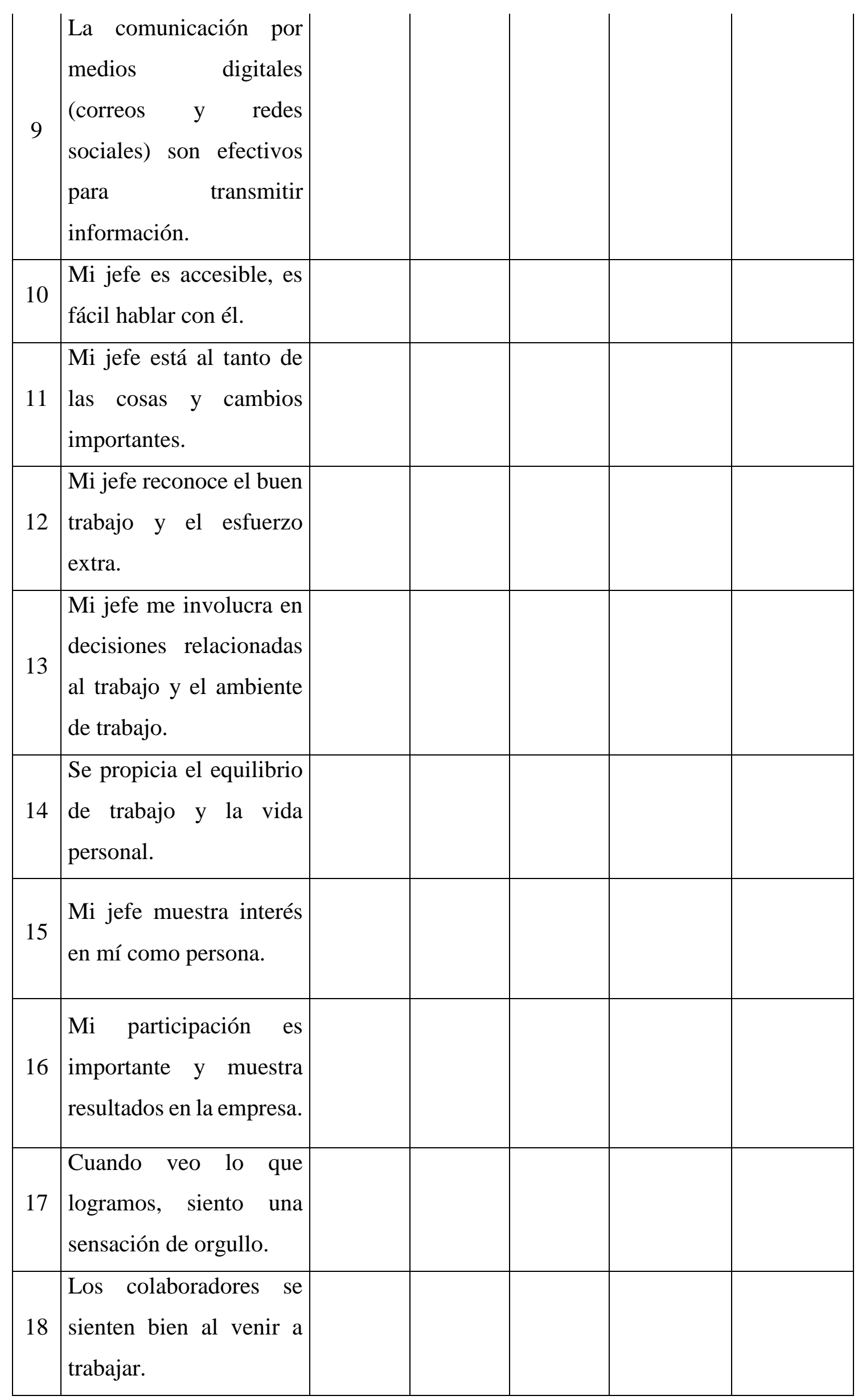




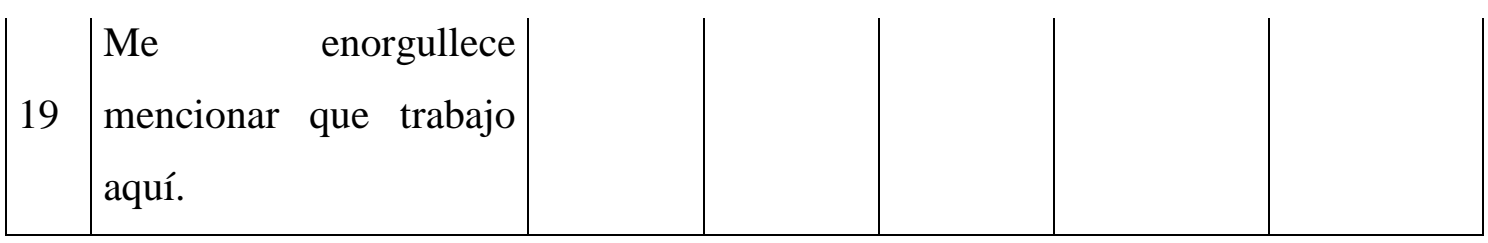


Anexo 2: Matriz de operacionalización de variables

\section{MATRIZ DE OPERACIONALIZACIÓN DE VARIABLES}

Título: La Comunicación organizacional y su influencia en el clima organizacional en los operarios de Industrias San Miguel en el 2017 Autor: Carol Reyes y Augusto Ayarza

\begin{tabular}{|c|c|c|c|c|c|c|c|}
\hline PROBLEMA & OBJETIVOS & HIPÓTESIS & & & RIABLES E INDICADO & RES & \\
\hline \multirow[b]{3}{*}{$\begin{array}{l}\text { Problema General: } \\
\text { ¿Cuál es la } \\
\text { influencia de la } \\
\text { comunicación } \\
\text { organizacional en el } \\
\text { clima } \\
\text { organizacional de } \\
\text { los operarios de } \\
\text { Industrias San } \\
\text { Miguel en el } 2017 ?\end{array}$} & \multirow{3}{*}{$\begin{array}{l}\text { Objetivo general: } \\
\text { Determinar la } \\
\text { influencia } \\
\text { significativa de la } \\
\text { comunicación } \\
\text { organizacional en } \\
\text { el clima } \\
\text { organizacional de } \\
\text { los operarios de } \\
\text { Industrias San } \\
\text { Miguel en el } 2017 .\end{array}$} & \multirow[b]{3}{*}{$\begin{array}{l}\text { Hipótesis general: } \\
\text { La comunicación } \\
\text { organizacional } \\
\text { influye } \\
\text { significativamente } \\
\text { en el clima } \\
\text { organizacional de } \\
\text { los operarios de } \\
\text { Industrias San } \\
\text { Miguel en el } 2017 .\end{array}$} & \multicolumn{5}{|c|}{ Variable 1: COMUNICACIÓN ORGANIZACIONAL } \\
\hline & & & Dimensiones & Indicadores & Ítems & $\begin{array}{l}\text { Escala de } \\
\text { medición }\end{array}$ & $\begin{array}{c}\text { Niveles o } \\
\text { rangos }\end{array}$ \\
\hline & & & $\begin{array}{c}\text { Comunicación } \\
\text { Interna }\end{array}$ & $\begin{array}{c}\text { Percepción } \\
\text { general }\end{array}$ & $\begin{array}{l}\text { 1. Existe una relación } \\
\text { positiva entre la } \\
\text { comunicación interna y } \\
\text { el clima organizacional. } \\
2 . \quad \text { Los empleados } \\
\text { pueden proponer } \\
\text { cambios en la } \\
\text { comunicación interna } \\
\text { para su mejora. }\end{array}$ & $\begin{array}{l}\text { (5) Siempre } \\
\text { (4) Casi Siempre } \\
\text { (3) A veces } \\
\text { (2) Casi Nunca } \\
\text { (1) Nunca }\end{array}$ & $\begin{array}{l}\text { Bajo (1-2) } \\
\text { Moderado } \\
(3-4) \\
\text { Alto (5) }\end{array}$ \\
\hline
\end{tabular}




\begin{tabular}{|c|c|c|c|c|c|}
\hline Problemas & Objetivos & Hipótesis & & & 3. Tengo una \\
\hline Específicos: & específicos: & específicas: & & & comunicación frecuente \\
\hline 1. ¿Cómo afecta la & 1. Analizar el & 1. La comunicación & & & con mi jefe directo. \\
\hline comunicación & efecto de la & interna afecta & & & 4. La comunicación \\
\hline interna en el clima & comunicación & positivamente en el & & & informal es positiva para \\
\hline organizacional de & interna en el clima & clima & & & el desarrollo del clima \\
\hline los operarios de & organizacional de & organizacional de & & & laboral. \\
\hline Industrias San & los operarios de & los operarios de & & & 5. Las \\
\hline Miguel en el 2017? & Industrias San & Industrias San & & & conversaciones \\
\hline 2. ¿Cuál es el & Miguel en el 2017. & Miguel en el 2017. & Canal Informal & Efectividad & informales influyen en \\
\hline impacto de la red de & 2. Conocer el & 2. Conocer como & & & la toma de decisiones. \\
\hline comunicación & impacto de la & impacta la red de & & & 6. Prefiero la \\
\hline formal en el clima & comunicación & comunicación & & & información publicada \\
\hline organizacional de & informal dentro de & formal en el clima & & & en los murales en lugar \\
\hline los operarios de & la estrategia de & organizacional de & & & de redes sociales y/o \\
\hline industrias San & comunicación & los operarios de & & & correos. \\
\hline Miguel en el 2017? & organizacional para & Industrias San & & & 7. La comunicación \\
\hline 3. ¿Cuál es el & el público operario & Miguel en el 2017. & & & informal brinda \\
\hline impacto de la red de & de Industrias San & 3. La red de & & & suficiente información. \\
\hline
\end{tabular}




\begin{tabular}{|c|c|c|c|c|c|c|c|}
\hline $\begin{array}{l}\text { comunicación } \\
\text { informal de los } \\
\text { operarios de } \\
\text { Industrias San } \\
\text { Miguel en el 2017? }\end{array}$ & $\begin{array}{l}\text { Miguel en el } 2017 . \\
\text { 3. Conocer como } \\
\text { impacta la red de } \\
\text { comunicación } \\
\text { informal en el } \\
\text { clima } \\
\text { organizacional de } \\
\text { los operarios de } \\
\text { Industrias San } \\
\text { Miguel en el } 2017 .\end{array}$ & \begin{tabular}{|l} 
comunicación \\
informal impacta \\
positivamente en el \\
clima \\
organizacional de \\
los operarios de \\
Industrias San \\
Miguel en el 2017.
\end{tabular} & Canal Formal & Efectividad & $\begin{array}{l}8 . \quad \text { La comunicación } \\
\text { formal satisface las } \\
\text { necesidades de } \\
\text { información. } \\
9 . \quad \text { La comunicación } \\
\text { por medios digitales } \\
\text { (correos y redes } \\
\text { sociales) son efectivos } \\
\text { para transmitir } \\
\text { información. }\end{array}$ & & \\
\hline \multirow[b]{2}{*}{$\begin{array}{l}\text { Tipo y diseño de } \\
\text { investigación }\end{array}$} & \multirow[b]{2}{*}{$\begin{array}{c}\text { Población y } \\
\text { muestra }\end{array}$} & \multirow[b]{2}{*}{$\begin{array}{c}\text { Técnicas e } \\
\text { instrumentos }\end{array}$} & \multicolumn{5}{|c|}{ Variable 2: CLIMA ORGANIZACIONAL } \\
\hline & & & Dimensiones & Indicadores & Ítems & $\begin{array}{l}\text { Escala de } \\
\text { medición }\end{array}$ & $\begin{array}{c}\text { Niveles o } \\
\text { rangos }\end{array}$ \\
\hline
\end{tabular}




\begin{tabular}{|c|c|c|c|c|c|c|c|}
\hline $\begin{array}{l}\text { Tipo: El tipo de } \\
\text { estudio aplicado. La } \\
\text { investigación } \\
\text { aplicada está muy } \\
\text { relacionada con la } \\
\text { investigación pura, } \\
\text { pues, en cierta } \\
\text { forma, la aplicada } \\
\text { depende de sus } \\
\text { hallazgos y } \\
\text { aportaciones } \\
\text { teóricas (Landeau, } \\
\text { 2007, pág. 55). Es } \\
\text { correlacional } \\
\text { (Hernández, } \\
\text { Fernández, \& } \\
\text { Baptista, 2010, pág. } \\
81 \text { ) }\end{array}$ & $\begin{array}{l}\text { Población: } 255 \\
\text { trabajadores de una } \\
\text { empresa de } \\
\text { consumo masivo. } \\
\text { Tipo de muestreo: } \\
\text { No Probabilístico. } \\
\text { Aleatorio Simple. } \\
\text { Tamaño de } \\
\text { muestra: Al 95\% } \\
\text { de confiabilidad y } \\
\text { tomando solo a los } \\
\text { colaboradores con } \\
\text { un mínimo de seis } \\
\text { meses en el puesto, } \\
\text { se tiene una } \\
\text { muestra de } 154 \\
\text { encuestas. }\end{array}$ & $\begin{array}{l}\text { Técnicas: Encuesta. } \\
\text { Instrumentos: } \\
\text { Cuestionario con } \\
\text { escala de Likert. } \\
\text { Autor: Elaboración } \\
\text { propia. } 2017 . \\
\text { Monitoreo: } \\
\text { estadístico } \\
\text { correlacional. } \\
\text { Ámbito de } \\
\text { Aplicación: Lima. } \\
\text { Planta } \\
\text { Embotelladora de } \\
\text { Industrias San } \\
\text { Miguel en Huaura. } \\
\text { Forma de } \\
\text { Administración: } \\
\text { Presencial. Impreso. }\end{array}$ & Credibilidad & Capacidad & $\begin{array}{l}\text { 10. Mi jefe es accesible, } \\
\text { es fácil hablar con él. } \\
\text { 11. Mi jefe está al tanto } \\
\text { de las cosas y cambios } \\
\text { importantes. } \\
\text { 12. Mi jefe reconoce el } \\
\text { buen trabajo y el } \\
\text { esfuerzo extra } \\
\text { 13. Mi jefe me } \\
\text { involucra en decisiones } \\
\text { relacionadas al trabajo y } \\
\text { el ambiente de trabajo. } \\
\text { 14. Se propicia el } \\
\text { equilibrio de trabajo y la } \\
\text { vida personal. }\end{array}$ & $\begin{array}{l}\text { (5) Siempre } \\
\text { (4) Casi Siempre } \\
\text { (3) A veces } \\
\text { (2) Casi Nunca } \\
\text { (1) Nunca }\end{array}$ & $\begin{array}{l}\text { Bajo (1-2) } \\
\text { Moderado } \\
(3-4) \\
\text { Alto (5) }\end{array}$ \\
\hline
\end{tabular}




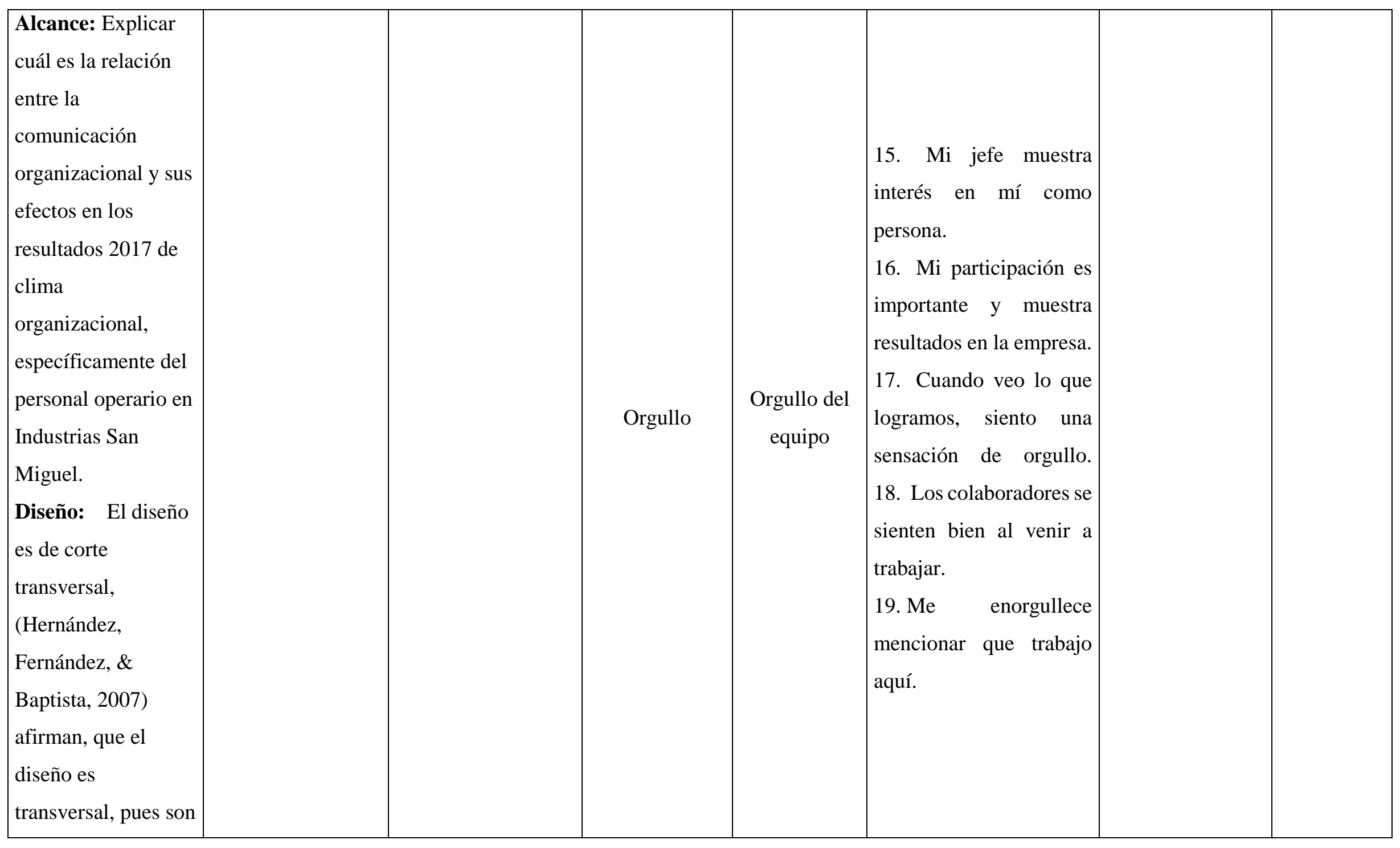




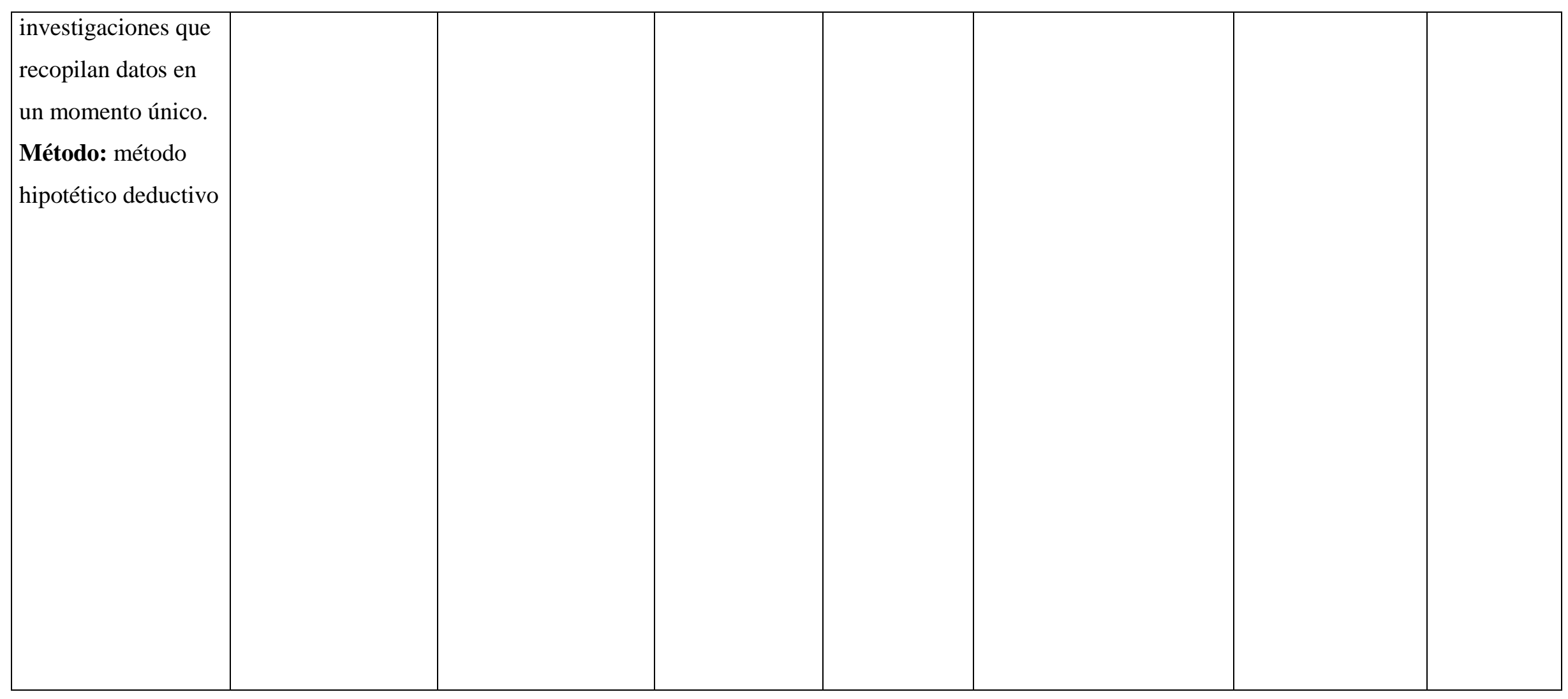

